\title{
Simulated Supercells in Nontornadic and Tornadic VORTEX2 Environments $\mathscr{a}$
}

\author{
Brice E. COFFER AND MATTHEW D. PARKER \\ Department of Marine, Earth, and Atmospheric Sciences, North Carolina State University, Raleigh, North Carolina
}

(Manuscript received 15 June 2016, in final form 9 August 2016)

\begin{abstract}
The composite near-storm environments of nontornadic and tornadic supercells sampled during the second Verification of the Origins of Rotation in Tornadoes Experiment (VORTEX2) both appear to be generally favorable for supercells and tornadoes. It has not been clear whether small differences between the two environments (e.g., more streamwise horizontal vorticity in the lowest few hundred meters above the ground in the tornadic composite) are actually determinative of storms' tornadic potential. From the VORTEX2 composite environments, simulations of a nontornadic and a tornadic supercell are used to investigate stormscale differences that ultimately favor tornadogenesis or tornadogenesis failure. Both environments produce strong supercells with robust midlevel mesocyclones and hook echoes, though the tornadic supercell has a more intense low-level updraft and develops a tornado-like vortex exceeding the EF3 wind speed threshold. In contrast, the nontornadic supercell only produces shallow vortices, which never reach the EF0 wind speed threshold. Even though the nontornadic supercell readily produces subtornadic surface vortices, these vortices fail to be stretched by the low-level updraft. This is due to a disorganized low-level mesocyclone caused by predominately crosswise vorticity in the lowest few hundred meters above ground level within the nontornadic environment. In contrast, the tornadic supercell ingests predominately streamwise horizontal vorticity, which promotes a strong low-level mesocyclone with enhanced dynamic lifting and stretching of surface vertical vorticity. These results support the idea that larger streamwise vorticity leads to a more intense lowlevel mesocyclone, whereas predominately crosswise vorticity yields a less favorable configuration of the lowlevel mesocyclone for tornadogenesis.
\end{abstract}

\section{Introduction}

Since the Verification of the Origins of Rotation in Tornadoes Experiment (VORTEX; Rasmussen et al. 1994) in the mid-1990s, considerable progress has been made regarding our recognition of the lower-tropospheric profiles of temperature, humidity, and winds that favor nontornadic versus tornadic supercells (Rasmussen and Blanchard 1998; Rasmussen 2003; Markowski et al. 2003; Thompson et al. 2003, 2007; Craven et al. 2004). However, it is still unclear how these differences in the environmental profiles, especially the lower-tropospheric wind profile, affect the in-storm processes that lead to tornadogenesis.

Supplemental information related to this paper is available at the Journals Online website: http://dx.doi.org/10.1175/ MWR-D-16-0226.s1.

Corresponding author address: Brice Coffer, North Carolina State University, Campus Box 8208, Raleigh, NC 27695-8208. E-mail: becoffer@ncsu.edu
Tornadogenesis within supercell thunderstorms has traditionally been thought of as a three-step process: 1) development of a midlevel ${ }^{1}$ mesocyclone via tilting of environmental horizontal vorticity into the vertical by the updraft, 2) generation of subtornadic ${ }^{2}$ surface vertical vorticity by a downdraft, and 3 ) the contraction of that surface vertical vorticity into a tornado (Davies-Jones and Brooks 1993; Davies-Jones 2015). Recent research using high-resolution simulations (e.g., Dahl et al. 2014; Markowski and Richardson 2014; Schenkman et al. 2014; Markowski 2016) has expanded on earlier seminal work (Davies-Jones 1982; DaviesJones and Brooks 1993) detailing the specific processes that enable step 2 of the tornadogenesis process. However, it seems that supercells produce near-ground

\footnotetext{
${ }^{1}$ In this paper, "midlevel" refers to $3-7 \mathrm{~km}$ above ground level (AGL), while "low level" refers to $\sim 1 \mathrm{~km}$ AGL, and "near surface" or "surface" will refer to $\leq 10 \mathrm{~m}$ AGL (the lowest model level grid point).

${ }^{2}$ In this paper, "subtornadic vorticity" will refer to mesocyclonic-scale vertical vorticity $\left(\geq 0.01 \mathrm{~s}^{-1}\right)$ at the surface.
} 
TABLE 1. Summary of common environmental forecasting parameters calculated from the steady-state nontornadic and tornadic VORTEX2 near-inflow composite soundings. The surface-based parcel is used for the convective available potential energy (CAPE; $\mathrm{J} \mathrm{kg}^{-1}$ ), convective inhibition (CIN; $\mathrm{J} \mathrm{kg}^{-1}$ ), and the lifted condensation level (LCL; $\mathrm{m}$ ). The effective environmental bulk vertical wind shear vector magnitude (kt) is simply referred to as effective shear (Thompson et al. 2007). Storm-relative helicity $\left(\mathrm{SRH} ; \mathrm{m}^{2} \mathrm{~s}^{-2}\right.$ ) was calculated using the Bunkers storm motion (Bunkers et al. 2000), which was similar to the simulated storm motion. The critical angle $\left(^{\circ}\right)$ is the angle between the 10-500-m wind shear vector and the 10-m wind vector (Esterheld and Giuliano 2008), and the supercell composite parameter (SCP; dimensionless) and significant tornado parameter (STP; dimensionless) utilize the CIN constraint and the effective inflow layer described by Thompson et al. (2007). All parameters were calculated using SHARPpy (Blumberg et al. 2016, manuscript submitted to Bull. Amer. Meteor. Soc.).

\begin{tabular}{|c|c|c|c|c|c|c|c|c|c|c|}
\hline & CAPE & $\mathrm{CIN}$ & LCL & Effective shear & 0-500-m SRH & 0-1-km SRH & Effective SRH & Critical angle & SCP & STP \\
\hline Nontornadic & 2377 & -43 & 1129 & 49 & 80 & 151 & 314 & 140 & 14.9 & 2.6 \\
\hline Tornadic & 2755 & -39 & 845 & 61 & 159 & 224 & 297 & 93 & 16.4 & 4.9 \\
\hline
\end{tabular}

rotation rather easily, regardless of the initial orientation of the low-level storm-relative winds (Dahl 2015; Parker and Dahl 2015). Observations of supercells have shown remarkable resemblance between nontornadic and tornadic supercells, including similar precipitation echoes, kinematic structures of the rear-flank outflow, and the presence of low-level mesocyclones and surface circulations (Trapp 1999; Wakimoto and Cai 2000; Wakimoto et al. 2004; Markowski et al. 2008, 2011; Klees et al. 2016). Despite these similarities, the majority of supercells (at least $75 \%$ ) do not produce tornadoes (Trapp et al. 2005). It is likely not a coincidence that the false alarm ratio for tornado warnings in the United States is also approximately 75\% (Brotzge et al. 2011). Unfortunately, we cannot yet explain what separates the ostensibly similar nontornadic supercells from tornadic supercells. What are the different processes that lead to either tornadogenesis or tornadogenesis failure, and can these processes be directly linked to the environment?

To address this gap in the knowledge base, during the second VORTEX field campaign (VORTEX2; Wurman et al. 2012), numerous near-supercell observations were collected in order to assess environmental variability and to further understand the relationship between the environment and tornadoes. Parker (2014) generated composite environments (from 134 nearstorm soundings) of the 12 best sampled VORTEX2 supercells; this included 7 tornadic and 5 nontornadic supercells. For this study, we focused on the composite VORTEX2 environments instead of individual soundings from VORTEX2 cases because there are countless differences between any two given cases, making it difficult to know whether any particular characteristic has general applicability to tornadogenesis (e.g., Markowski 2008). Our current philosophy is that this difficulty can only be overcome by finding relationships between storm attributes and aspects of environments that are representative of a large number of cases.

Both the nontornadic and tornadic near-inflow composite soundings from Parker (2014) are seemingly favorable for tornadoes, with convective available potential energy (CAPE) values greater than $2000 \mathrm{~J} \mathrm{~kg}^{-1}$ and storm-relative helicity (SRH) near $300 \mathrm{~m}^{2} \mathrm{~s}^{-2}$ in the effective inflow layer (Table 1). In fact, each profile has a significant tornado parameter that is above the climatological median for EF3+ tornadoes (Thompson et al. 2012). The most noticeable difference between the nontornadic and tornadic composites is in the lower-tropospheric wind profile; specifically, the orientation of the 0-500-m shear vector with respect to the storm-relative inflow implies that the tornadic cases have much more streamwise horizontal vorticity in the lowest $500 \mathrm{~m}$ AGL (Fig. 1).

While lower-tropospheric SRH is typically reported for the $0-1-\mathrm{km}$ layer, it has been previously noted that even shallower layers may be more skillful for tornado forecasting (Rasmussen 2003). Using observed proximity soundings, Esterheld and Giuliano (2008) showed that SRH integrated over the 0-500-m layer provided the best discrimination between nontornadic and tornadic supercells. Additionally, the angle between the 0-500-m AGL shear vector and the 10-m storm-relative inflow vector (referred to as the "critical angle") was most commonly near $90^{\circ}$ for the significantly tornadic supercells (indicating purely streamwise horizontal vorticity). Meanwhile for the nontornadic supercells, the critical angle was much more frequently near $110^{\circ}$ (indicating partially crosswise horizontal vorticity). In the VORTEX2 dataset, the 0-500-m SRH is considerably higher in the tornadic composite compared to the nontornadic (159 vs $80 \mathrm{~m}^{2} \mathrm{~s}^{-2}$, respectively) and, just as in Esterheld and Giuliano (2008), the critical angle is approximately $90^{\circ}$ for the tornadic environment, whereas the nontornadic environment has a critical angle of $140^{\circ}$ (Table 1, Fig. 1). Increased streamwise vorticity and SRH in the lowest few hundred meters should promote a stronger low-level mesocyclone in a supercell and thereby stronger dynamic lifting. This lifting, in turn, may increase the likelihood of tornadogenesis (Markowski et al. 2012b; Markowski and Richardson 2014; Skinner et al. 2014; Coffer and Parker 2015). The 


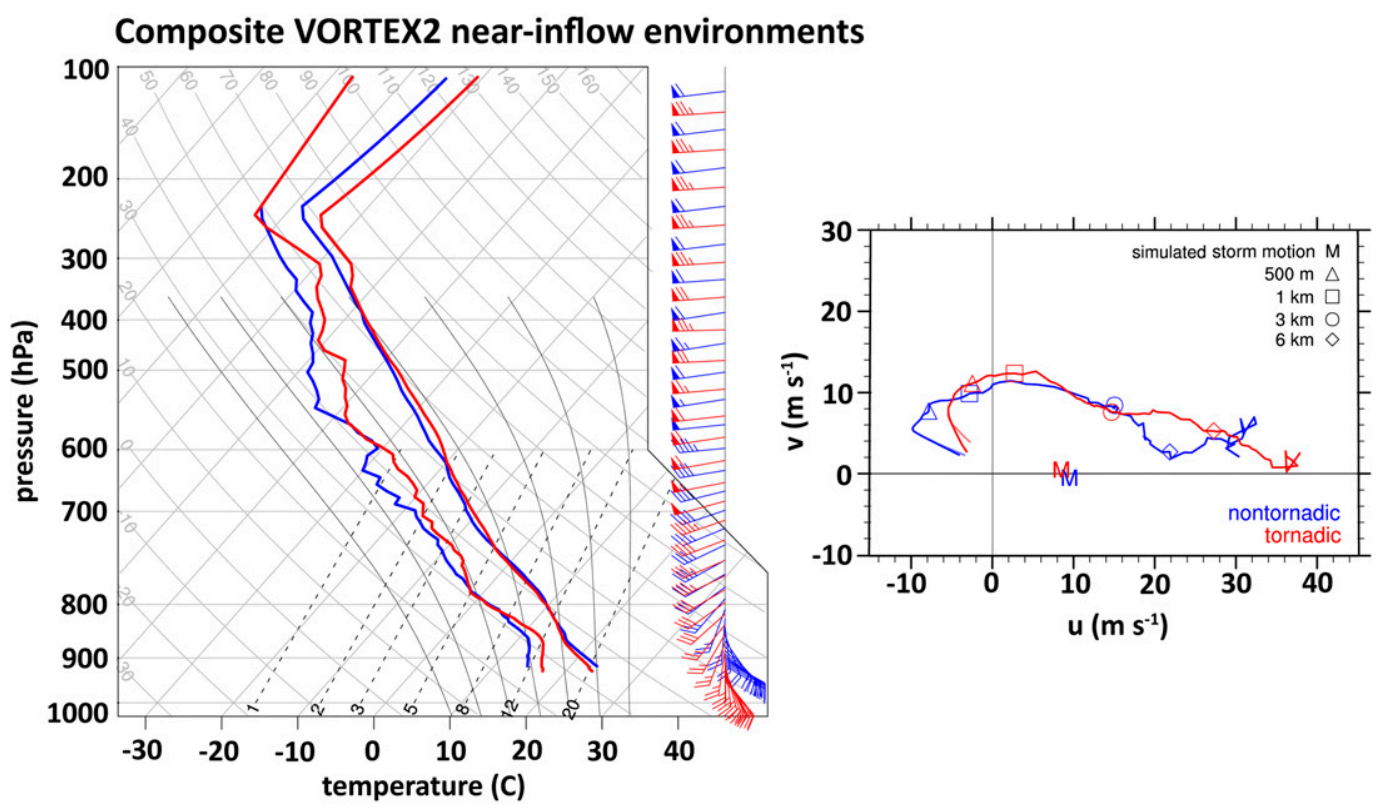

FIG. 1. (left) Skew $T-\log p$ diagram and (right) hodograph showing the steady-state nontornadic (blue) and tornadic (red) VORTEX2 near-inflow composite soundings. The initial nontornadic and tornadic VORTEX nearinflow wind-profiles are superimposed on the hodograph (subtle differences are confined to the lowest $\sim 200 \mathrm{~m}$ ). The simulated storm motion is indicated on the hodograph by the "M." Markers on the hodograph represent $500 \mathrm{~m}$ (triangle), $1 \mathrm{~km}$ (square), $3 \mathrm{~km}$ (circle), and $6 \mathrm{~km}$ (diamond) AGL. The wind barbs on the skew $T-\log p$ are displayed in $\mathrm{kt}\left(1 \mathrm{kt}=0.5144 \mathrm{~m} \mathrm{~s}^{-1}\right)$. See Parker (2014) for more discussion on the generation and interpretation of the VORTEX2 composite environments.

orientation of the lower-tropospheric winds in the nontornadic cases may also alter the interaction between the cold pool and vertical wind shear, which in some cases leads to an unfavorable, backward-tilted updraft orientation (Nowotarski 2015). Although strong to violent tornadoes can occur in environments with nearly straight hodographs (see Davies-Jones et al. 2001, their Table 5.1 and discussion thereof), after the initial storm-splitting process, the right-moving supercell typically has appreciable near-surface streamwise horizontal vorticity, as in the tornadic VORTEX2 composite environment. Examples of such tornadoes include the Wichita Falls, Texas, tornado of 3 April 1964 (Charba and Sasaki 1968; DaviesJones et al. 2001, see their Fig. 5.9) and the Union City, Oklahoma, tornado of 24 May 1973 (Lemon et al. 1978, see their Fig. 2).

The purpose of this paper is to explore contrasting storm-scale characteristics of full-physics supercell simulations initialized with the nontornadic and tornadic pair of VORTEX2 composite environments. We use these simulations to address the following questions:

1) Do the two VORTEX2 composite soundings contain sufficiently distinct ingredients to "correctly" simulate nontornadic and tornadic supercells in the respective nontornadic and tornadic environments?
2) If so, what is the failure point for tornadogenesis in the nontornadic supercell compared to the tornadic supercell?

3) Finally, can this failure point be specifically traced to some trait that differs between the nontornadic and tornadic environments?

The methods are described in section 2, while general comparisons of the evolution between the nontornadic and tornadic simulations are discussed in section 3 . Additionally in section 3, unique aspects of the individual supercells are detailed more comprehensively, and then specific storm-scale differences that lead to tornadogenesis (or the lack thereof) are described in section 4. Clearer cause-effect is then gleaned from simpler "toy model" simulations, which are explored in section 5 . We conclude with a synthesis of the main findings and avenues for future work.

\section{Methods}

\section{a. Model configuration}

To examine potentially relevant differences between storms in the nontornadic and tornadic VORTEX2 composite environments, supercell simulations were conducted using release 17 of Cloud Model version 1 [CM1; see the 
appendix of Bryan and Morrison (2012)]. These storms were simulated for $2 \mathrm{~h}$ on a $200 \times 200 \times 18 \mathrm{~km}^{3}$, horizontally homogeneous domain initialized using the near-inflow composite VORTEX2 soundings discussed previously [Fig. 1; for more detailed information on the generation of the VORTEX2 composites see Parker (2014), 509-516]. The near-inflow soundings from VORTEX2 were taken approximately $40 \mathrm{~km}$ to the southeast of the storm's updraft (Parker 2014); proximity soundings near this distance have been shown to be close enough to be representative of the background environment, yet distant enough to minimize convective feedbacks (Potvin et al. 2010). For rapid data collection, near-storm soundings during VORTEX2 were usually terminated at the approximate height of the tropopause. A potential temperature inversion of $20 \mathrm{~K} \mathrm{~km}^{-1}$ with $1 \%$ relative humidity and constant winds was used as an approximation for stratospheric data. Convection was initiated using the updraft nudging technique described by Naylor and Gilmore (2012), and the simulations use a six-category, fully double-moment bulk microphysics scheme from the National Severe Storms Laboratory (NSSL) that explicitly predicts the variable densities of hail and graupel (Ziegler 1985; Mansell 2010; Mansell et al. 2010). The horizontal grid spacing is $125 \mathrm{~m}$ within a $100 \times 100 \mathrm{~km}^{2}$ inner domain centered on the rightmoving supercell and gradually increases to $3.875 \mathrm{~km}$ at the edges of the domain (Wilhelmson and Chen 1982). The lowest scalar grid level is at $10 \mathrm{~m}$, and from there, the vertical grid spacing stretches from $20 \mathrm{~m}$ in the lowest $300 \mathrm{~m}$ to $280 \mathrm{~m}$ at $12 \mathrm{~km}$, allowing for 31 levels in the lowest kilometer. The model time step was $0.6 \mathrm{~s}$, with eight split time steps for the acoustic modes (Klemp and Wilhelmson 1978). A fifth-order advection scheme, utilizing high-order-weighted essentially nonoscillatory finite differencing, is used with no additional artificial diffusion (Wicker and Skamarock 2002; Shu 2003). The subgrid-scale turbulence is parameterized by a 1.5 -order turbulence kinetic energy closure scheme similar to Deardorff (1980), with separate horizontal and vertical turbulence coefficients. Open, radiative lateral boundary conditions were employed, while the upper-boundary has a rigid, free-slip boundary condition, with a Rayleigh damping sponge applied above $14 \mathrm{~km}$. The bottom boundary condition is semislip and is described in more detail below.

\section{b. Semislip bottom boundary condition}

Idealized simulations of supercell thunderstorms have almost exclusively been conducted using a free-slip (i.e., frictionless) bottom boundary condition. In these simulations, it has generally been found that the tilting of baroclinically generated horizontal vorticity by downdrafts near the surface produces intense, tornadolike vortices (e.g., Rotunno and Klemp 1985; Wicker and Wilhelmson 1995; Adlerman et al. 1999; Dahl et al. 2014; Dahl 2015; Markowski and Richardson 2014). Observations of tornadic supercells also heavily suggest the influence of baroclinity (Markowski 2002; Markowski et al. 2012a,b; Straka et al. 2007; Marquis et al. 2012). However, recently, frictional generation of vorticity has been investigated in supercell simulations and at times been found to be an appreciable contributor to the vorticity budget (Schenkman et al. 2014; Roberts et al. 2016), even though baroclinic generation likely dominates once the storm's cold pool is established (Markowski 2016). It is also well established that surface drag is crucial for disrupting cyclostrophic balance and inducing strong radial inflow into a developing tornado (Davies-Jones 2015). Although incorporating surface friction into idealized convective simulations presents difficulties (Markowski and Bryan 2016), we have applied a constant surface drag coefficient $\left(C_{d}\right)$ of 0.0014 in an attempt to partially capture frictional effects on within-storm processes. This $C_{d}$ value was calculated in CM1 from the composite VORTEX2 rear-flank outflow sounding (Parker 2014, see their Fig. 9) using the surface layer scheme developed by Jiménez et al. (2012), with a land-use-type set to summertime "irrigated cropland" (defined by the U.S. Geological Survey). In contrast, the computed value of $C_{d}$ from the composite VORTEX2 near-inflow sounding (e.g., Fig. 1) was approximately 0.005, similar to those reported in Frame and Markowski (2010) and Nowotarski et al. (2015). However, the rear-flank outflow is the main area of interest for vorticity generation and tornadogenesis (e.g., Rotunno and Klemp 1985; Wicker and Wilhelmson 1995; Dahl et al. 2014; Markowski and Richardson 2014); thus, the smaller $C_{d}$ value (based on the outflow profile with higher static stability) was used. This smaller value of $C_{d}$ also lessens the potential for surface drag to excessively modify the near-ground vertical wind shear (as explained by Markowski and Bryan 2016). Future work could investigate the effect of varying values of $C_{d}$ (and roughness length) upon the development of nearground rotation. Our philosophy is that the inclusion of modest surface drag represents a more physically consistent bottom boundary condition for tornadogenesis than does the habitually employed free-slip assumption.

In the absence of a large-scale pressure gradient force, surface drag continually slows the base-state near-ground wind profile in idealized, horizontally 
homogeneous simulations. To minimize this slowing, the Coriolis force was applied to the perturbation winds (i.e., subtracting the base-state wind profile from the full horizontal velocity field). This is equivalent to assuming that the initial wind profile is in geostrophic balance, introducing a force that opposes and offsets frictional effects once a new steady state is acquired [see Eqs. (7)-(8) of Roberts et al. (2016)]. Of course, the observed VORTEX2 profiles already include boundary layer modifications from surface drag and are therefore not truly geostrophic, but the resulting adjustments of the wind profile is nevertheless quite small using this assumption, as we describe next.

Since both surface drag and the Coriolis force affect the base state slowly, each environmental profile was first simulated in a small-domain simulation with the same model configuration described in section $2 \mathrm{a}$ (except for periodic lateral boundaries and no convection initialization). The Coriolis parameter was set to a typical midlatitude value of $f=10^{-4} \mathrm{~s}^{-1}$. After roughly $4 \mathrm{~h}$, the wind profile in the lowest $200 \mathrm{~m}$ arrived at a quasisteady state. Each of the horizontally homogeneous supercell simulations discussed herein are therefore initialized using a wind profile extracted at this time ( $t=$ $4 \mathrm{~h}$ ). The differences between the initial and steady-state profiles were rather small (Table 2, Fig. 1), and with this treatment, the far inflow environment remains nearly steady state throughout the 2-h full-physics simulation. Although the supercells remain centered in the finemesh domain using a horizontal grid translation (making the model winds effectively "storm relative"), the surface momentum fluxes were calculated using the ground-relative wind speeds. Lower-resolution supercell simulations showed similar trends in storm structure, updraft strength, and near-surface vertical vorticity evolution between supercells that traversed across a fixed domain versus those that were centered in a moving grid with this treatment.

\section{Evolution of the nontornadic and tornadic supercells}

\section{a. Environmental characteristics}

The nontornadic and tornadic simulations are initialized with the near-inflow soundings (with wind profile adjustments explained in section $2 b$ ) composited from the five nontornadic supercells and seven tornadic supercells best observed during VORTEX2 (Parker 2014). The nontornadic composite represents high-end null supercell cases, which are particularly problematic for operational warnings and, thus, quite intriguing to analyze. Both composite soundings possess ample CAPE,
TABLE 2. Summary of $0-500-\mathrm{m}$ wind shear magnitude $\left(\mathrm{m} \mathrm{s}^{-1}\right)$ and storm-relative helicity $\left(\mathrm{SRH} ; \mathrm{m}^{2} \mathrm{~s}^{-2}\right)$ for the initial and steadystate nontornadic and tornadic VORTEX2 composite wind profiles. The parameters for the steady-state simulations were computed at $t=4 \mathrm{~h}$ in the small-domain simulation described in section $2 \mathrm{~b}$. The environmental bulk vertical wind shear vector magnitude is simply referred to as shear, and SRH was calculated using the Bunkers storm motion (Bunkers et al. 2000).

\begin{tabular}{lcc}
\hline & $0-500-\mathrm{m}$ shear & $0-500-\mathrm{m} \mathrm{SRH}$ \\
\hline Nontornadic & & \\
$\quad$ Initial & 6.9 & 85.3 \\
$\quad$ Steady state & 6.7 & 80.2 \\
Tornadic & 7.2 & \\
$\quad$ Initial & 8.3 & 137.7 \\
$\quad$ Steady state & & 158.6 \\
\hline
\end{tabular}

modest convective inhibition (CIN), low lifted condensation level (LCL) heights, and sufficient vertical wind shear (Table 1). These combined ingredients lead to an effective-layer supercell composite parameter (SCP) of 14.9 and 16.4 and a significant tornado parameter (STP) of 2.6 and 4.9 in the nontornadic and tornadic environments, respectively. In bulk, the nontornadic and tornadic composite environments are rather similar and both would generally be considered favorable for supercells and tornadoes [nontornadic environments are typically associated with STP values less than 1 in the model-derived proximity soundings of Thompson et al. (2003), (2007)]. While the individual parameters are slightly more impressive in the tornadic environment, the differences are not particularly striking. Curiously, the effective inflow SRH, one of the components of the STP, is actually higher in the nontornadic environment.

\section{b. General differences between the nontornadic and tornadic supercells}

For the first $20 \mathrm{~min}$ of each simulation, a large amount of precipitation develops in response to the updraftnudging initialization technique. Afterward, in both cases, a dominant, cyclonic, right-moving storm begins to take on supercellular reflectivity structures (Figs. 2 and 3), and weaker disorganized convection moves north into the outer mesh (not shown). The supercell initialized in the tornadic VORTEX2 environment organizes at low levels 10-15 min sooner than the supercell initialized in the nontornadic VORTEX2 profile. During their most intense phase, the two supercells look remarkably similar in terms of reflectivity (cf. Figs. 2e and 3h). Both storms possess a strong updraft in the midlevels (i.e., $3-7 \mathrm{~km}$ AGL), with vertical velocities exceeding $40 \mathrm{~m} \mathrm{~s}^{-1}$ (Fig. 4). Despite these similarities, the low-level (i.e., $\sim 1 \mathrm{~km} \mathrm{AGL}$ ) updraft in the tornadic VORTEX2 supercell is much stronger; velocities greater than $35 \mathrm{~m} \mathrm{~s}^{-1}$ are often present as low as $500 \mathrm{~m}$ AGL. Since both environments have 


\section{Tornadic}

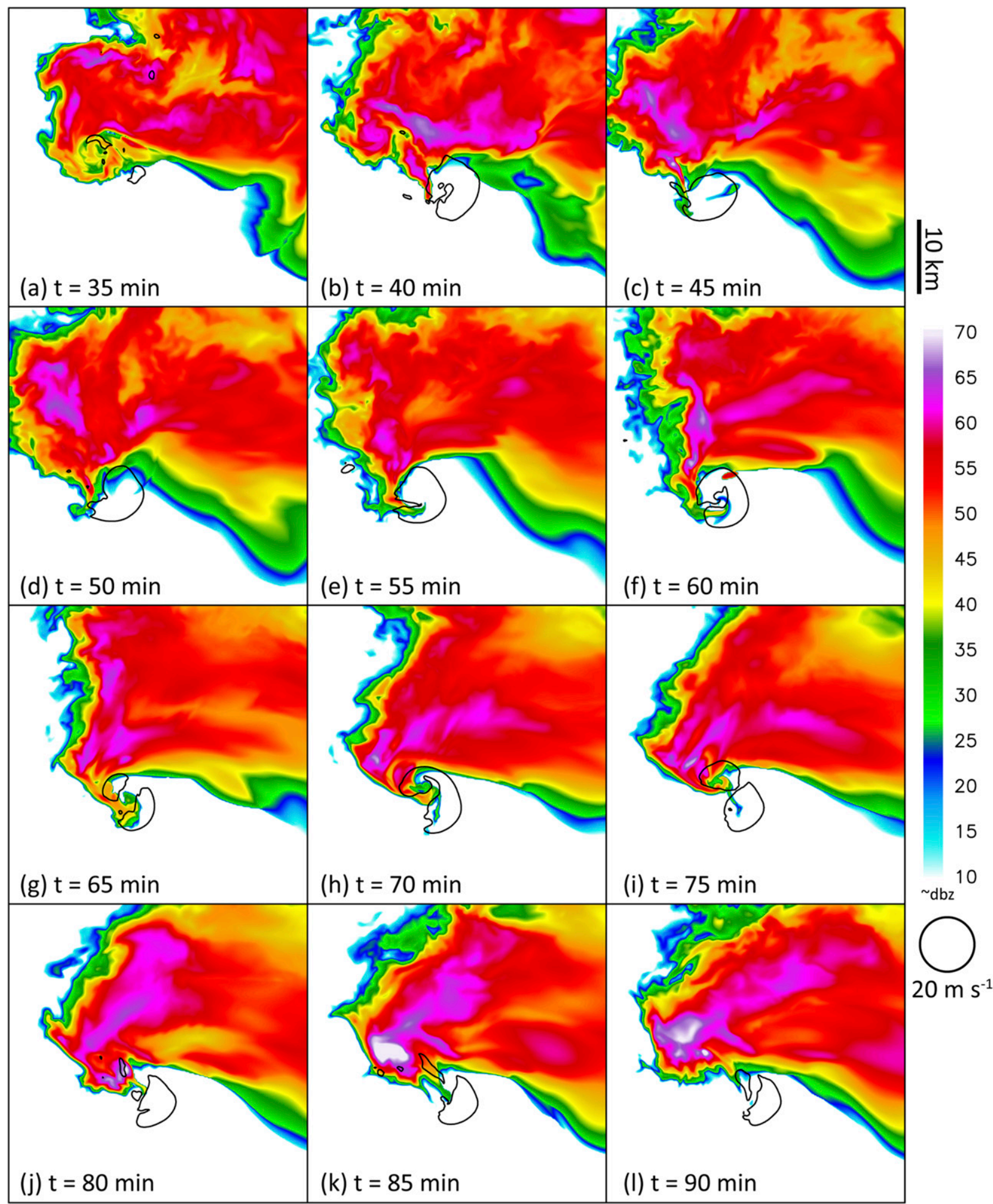

FIG. 2. Horizontal cross sections of 500-m model-simulated reflectivity and $20 \mathrm{~m} \mathrm{~s}^{-1}$ vertical velocity at $3 \mathrm{~km}$ AGL (black contour) at 5-min intervals from $t=35$ to $90 \mathrm{~min}$ for the tornadic supercell. 


\section{Nontornadic}

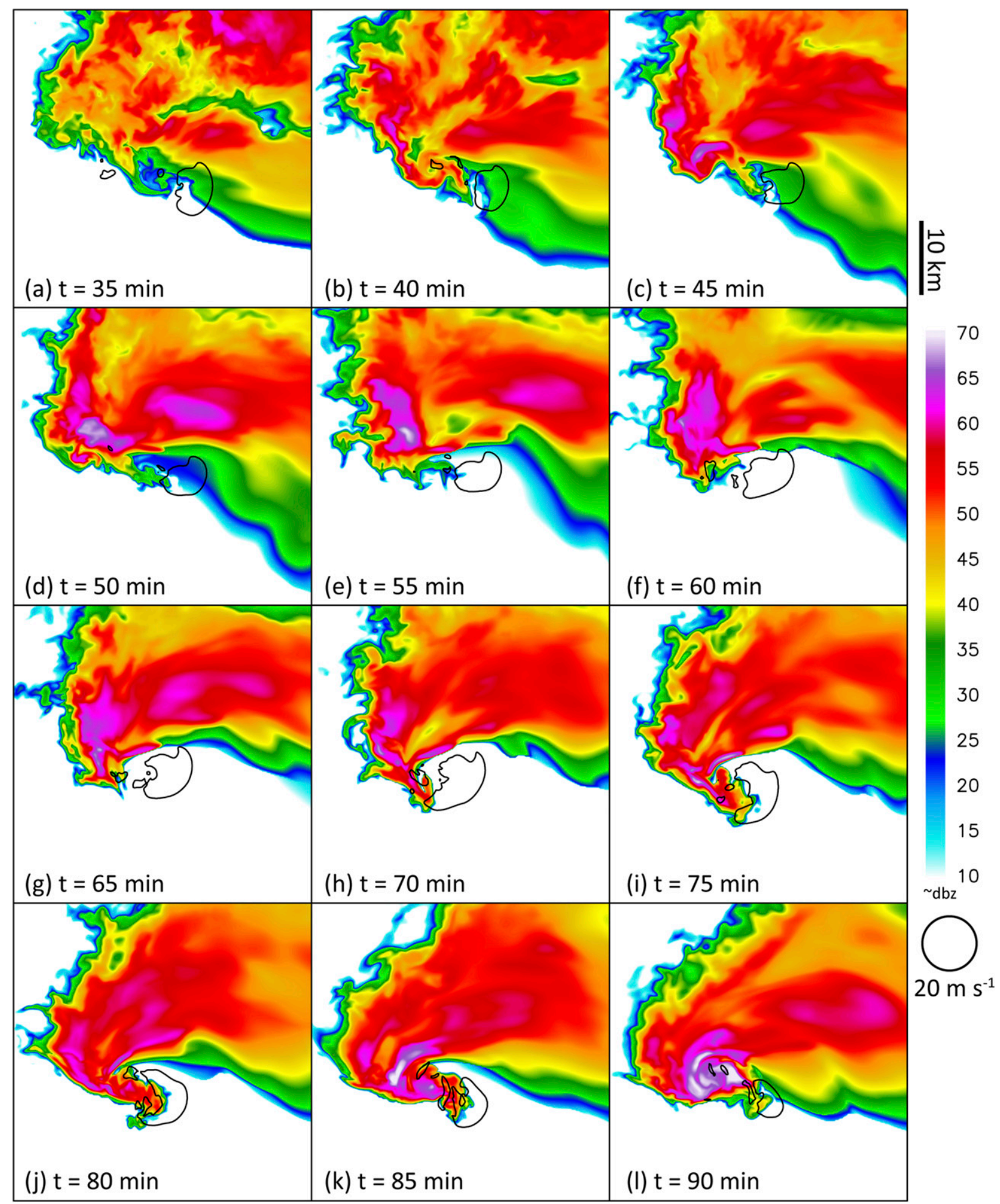

FIG. 3. As in Fig. 2, but for the nontornadic supercell. 

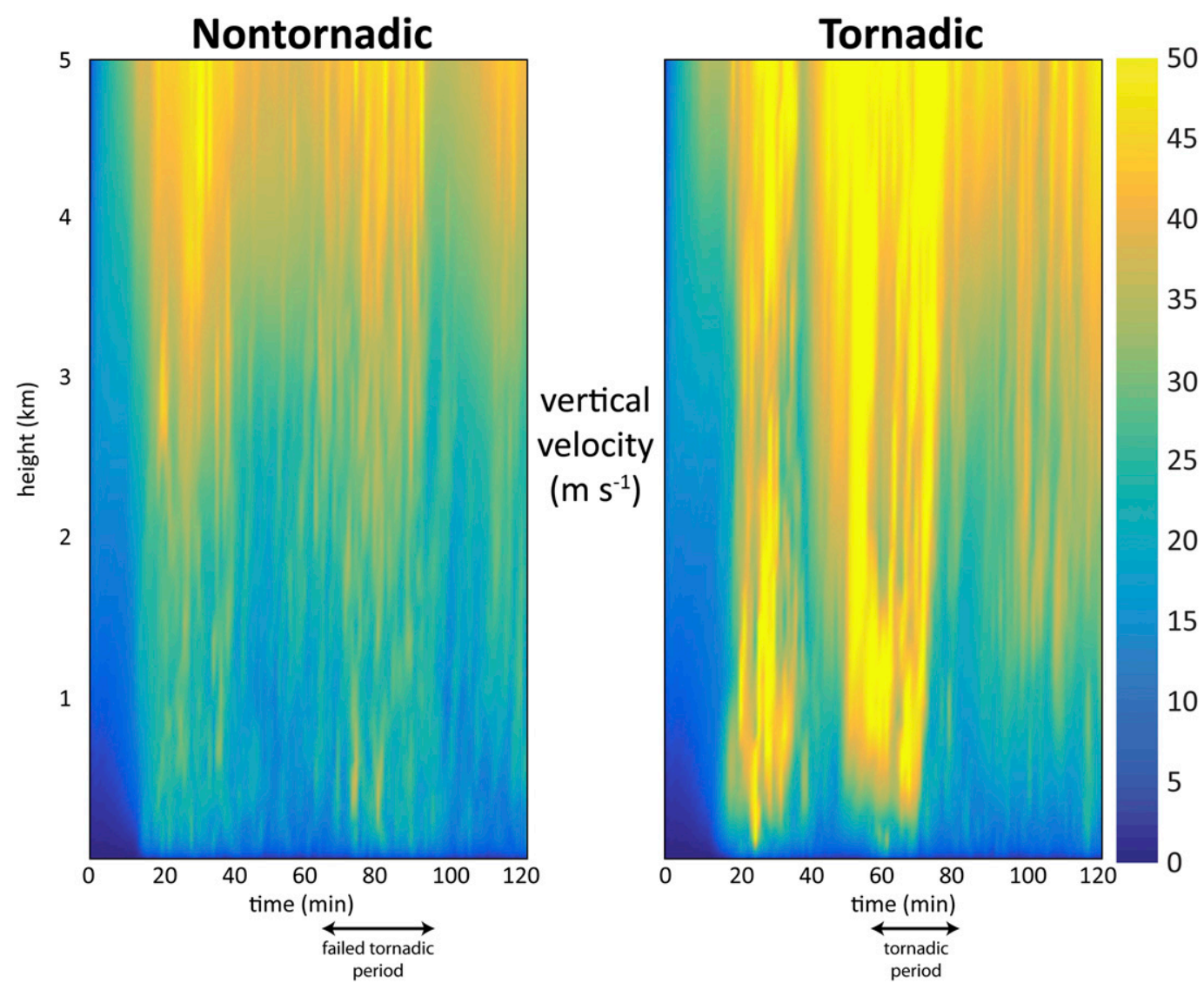

FIG. 4. Time-height plot of the maximum vertical velocity $\left(\mathrm{m} \mathrm{s}^{-1}\right)$ in a $50 \mathrm{~km}^{2}$ box following the midlevel mesocyclone for (left) the nontornadic supercell and (right) the tornadic supercell.

similar values of surface-based CAPE and CIN, these differences in the updraft velocity are likely due to dynamical influences. In turn, the contrasting low-level updrafts may eventually alter the intensification of surface vortices (e.g., through stretching). The nontornadic VORTEX2 supercell produces weak (never reaching the EF0 wind speed threshold), shallow (extending $<1 \mathrm{~km}$ AGL), transient (lasting a few minutes or less) surface vortices (Fig. 5). In contrast, the tornadic VORTEX2 supercell develops intense, long-lasting surface vortices. ${ }^{3}$

\footnotetext{
${ }^{3}$ The vortex that develops from $t \approx 15-35 \mathrm{~min}$ is induced by the updraft nudging convection initiation and compensating subsidence (similar to Parker 2012), combined with Coriolis force on the perturbation winds, and hence not the subject of the forthcoming analysis. Although vortices prior to the arrival of cool surface outflow have recently been evaluated by Markowski (2016) and Roberts et al. (2016), it is uncertain if these are relevant to real convective storms. Interestingly, although equal updraft forcing and Coriolis acceleration were applied in both simulations, the early near-surface vortex is much more intense in the simulation initialized with the tornadic VORTEX2 environment containing near-surface streamwise horizontal vorticity.
}

The tornado-like vortex (hereafter, simply "tornado") that develops at $t=55 \mathrm{~min}$ reaches a peak surface vertical vorticity of $1.1 \mathrm{~s}^{-1}$, a maximum $10-\mathrm{m}$ wind speed over $70 \mathrm{~m} \mathrm{~s}^{-1}$ ( $\sim 160 \mathrm{mph}$; corresponding to the criteria for a high-end EF3 tornado), and lasts for approximately $25 \mathrm{~min}$ (Fig. 5).

Bulk differences in low-level updraft strength and vertical vorticity imply that the two VORTEX2 composite soundings do indeed contain sufficiently distinct ingredients to "correctly" simulate nontornadic and tornadic supercells, which is rather remarkable. The subsequent goals of this study are to document and explain the processes that lead to these storm-scale differences and then establish how those processes are directly linked to the corresponding environments. To do this, we next explore the basic chronology of each supercell individually, starting with the tornadic supercell. Thereafter, we address the specific processes that result in tornadogenesis (or the lack thereof) in section 4.

\section{c. Tornadic supercell}

The cyclonically rotating right-mover exhibits supercellular structures by $t=40 \mathrm{~min}$ in the tornadic simulation 

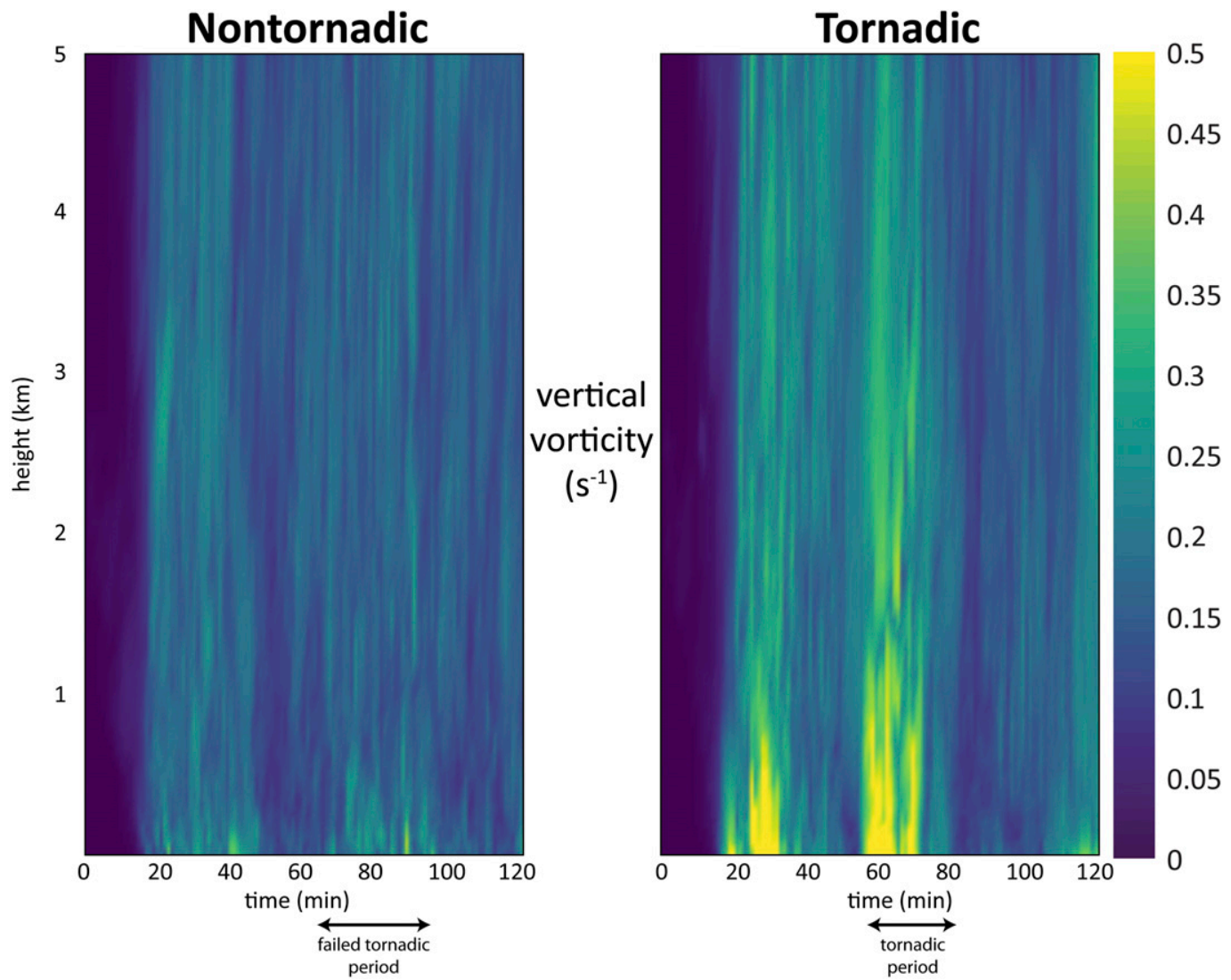

FIG. 5. As in Fig. 4, but for the maximum vertical vorticity $\left(\mathrm{s}^{-1}\right)$.

(Fig. 2b). By $t=45$ (Fig. 6), the midlevel updraft (Fig. 2c) is directly above the intersection of the rear- and forward-flank outflow boundaries near the hook echo (Figs. 6a,c), where widespread values of subtornadic surface vertical vorticity can be found (Fig. 6d). The low-level updraft at $1 \mathrm{~km}$ already exceeds $25 \mathrm{~m} \mathrm{~s}^{-1}$ and a broad area of ascent greater than $10 \mathrm{~m} \mathrm{~s}^{-1}$ exists throughout the weak echo region (Fig. 6b). Interestingly, as the low-level updraft is intensifying, precipitation cells develop in the inflow region out ahead of the hook echo and subsequently merge with the forward-flank precipitation (e.g., Fig. 6a).

An elongated zone of surface vertical vorticity, extending toward the rear-flank outflow boundary from the forward-flank precipitation region of the supercell, develops just prior to $t=40 \mathrm{~min}$ (visible at $t=45 \mathrm{~min}$ in Fig. 6d). Because this zone has both cyclonic shear vorticity and air parcels moving parallel to the corridor, we will refer to this as a vorticity river, consistent with the terminology of Dahl et al. (2014). As the supercell evolves, parcels from the vorticity river ultimately feed into the tornado (Figs. 7 and 8). Other studies, through both observations and simulations, have referred to similar phenomena as vorticity feeders (Fujita et al. 1976, see their Fig. 25), vortex sheets (e.g., Markowski et al. 2014), left-flank convergence boundaries (Beck and Weiss 2013, the vorticity rivers are focused along the left-flank convergence boundary), or just shear boundaries (Brandes 1978, see his Fig. 18). At $t=$ $45 \mathrm{~min}$, the vorticity river is characterized by vertical vorticity of $0.02 \mathrm{~s}^{-1}$ near the surface (Fig. 6d), and is associated with a gradient in density potential temperature (Fig. 6c), localized confluent horizontal velocity field (Fig. 6c), and streamwise horizontal vorticity vectors (Fig. 6d), much like those discussed by Dahl et al. (2014).

During the $15 \mathrm{~min}$ prior to tornadogenesis in the tornadic supercell, the low-level mesocyclone (i.e., $\sim 1 \mathrm{~km}$ AGL) dramatically strengthens. The core of the updraft begins to extend toward lower levels, with maximum velocities at $1 \mathrm{~km}$ increasing from 20 to $55 \mathrm{~m} \mathrm{~s}^{-1}$, and the mesocyclone aloft rapidly intensifies (Figs. 4 and 9a-c). At the surface, the vorticity river has rotated into a northsouth orientation near tornadogenesis time (Fig. 7d). During the intensification phase, the difference in density 


\section{Tornadic $\quad t=\mathbf{4 5} \mathrm{min}$}

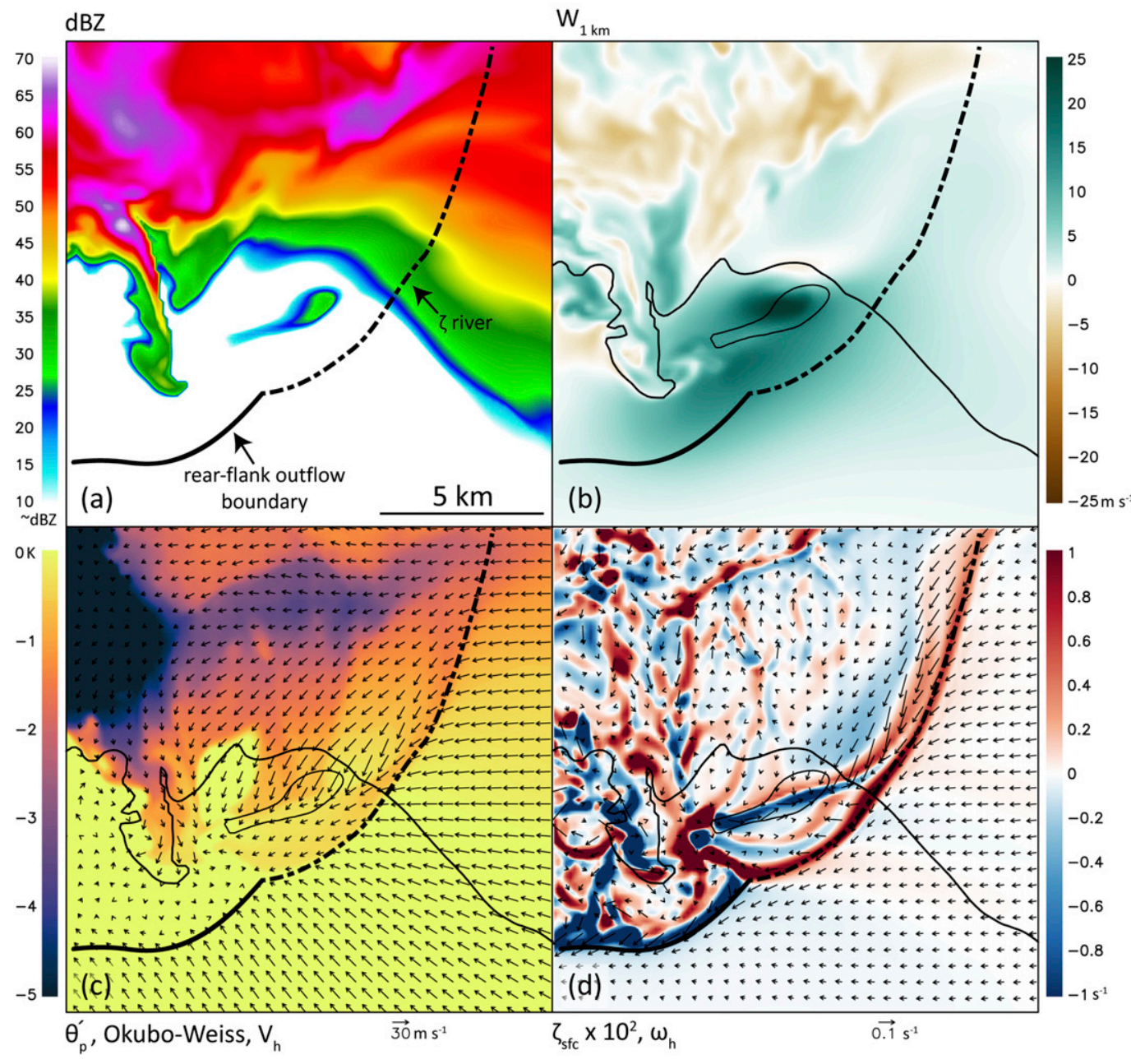

FIG. 6. Horizontal cross section from the tornadic supercell at $t=45 \mathrm{~min}$. (a) The $500-\mathrm{m}$ model-simulated reflectivity ( $\sim \mathrm{dBZ}$; shaded) and manually annotated boundaries. (b) The 1-km vertical velocity ( $\mathrm{m} \mathrm{s}^{-1}$; shaded) and 10-dBZ reflectivity at $500 \mathrm{~m}$ AGL (black contour). (c) The $10-\mathrm{m}$ density potential temperature perturbation (K; shaded), $10-\mathrm{dBZ}$ reflectivity at $500 \mathrm{~m}$ AGL (black contour), $10-\mathrm{m}$ Okubo-Weiss parameter greater than $0.01 \mathrm{~s}^{-2}$ (filled cyan contour, if present), and $10-\mathrm{m}$ storm-relative, horizontal wind vectors. (d) The $10-\mathrm{m}$ vertical vorticity $\left(\times 10^{2} \mathrm{~s}^{-1}\right.$; shaded), 10-dBZ reflectivity at $500 \mathrm{~m}$ AGL (black contour), and 10-m storm-relative, horizontal vorticity vectors. For both (c) and (d) every fourth vector is plotted. Boundary annotations were determined subjectively based on density potential temperature perturbations and the wind field. See also an animated version of this figure for the tornadic supercell from $t=40$ to 90 min (every $60 \mathrm{~s} ; 100$ times the normal speed) in the online supplemental material.

potential temperature ${ }^{4}$ across the vorticity river is approximately $1 \mathrm{~K} \mathrm{~km}^{-1}$, with colder density potential temperature to its west [i.e., $\nabla_{\theta_{\rho}}$ points from west to east implying baroclinic generation of streamwise vorticity as

\footnotetext{
${ }^{4}$ Density potential temperature $\theta_{\rho}$ is defined by $\theta_{\rho}=$ $\theta\left(1+0.61 q_{v}-q_{\text {hyd }}\right)$, where $\theta$ is the potential temperature, $q_{v}$ is the water vapor mixing ratio, and $q_{\text {hyd }}$ is the aggregated mixing ratio of all hydrometeors (Emanuel 1994). Density potential temperature perturbations are directly proportional to buoyancy.
}

in Davies-Jones and Brooks (1993), their Fig. 7c]. Air with highly streamwise horizontal vorticity (plus appreciable vertical vorticity) appears to flow through the vorticity river and then curves cyclonically into the developing tornado (Figs. 7d and 8d).

After the extended period of low-level mesocyclone intensification, an intense tornado develops at $t=$ $55 \mathrm{~min}$, rapidly increasing from surface vertical vorticity values of $0.2 \mathrm{~s}^{-1}$ to values greater than $1.1 \mathrm{~s}^{-1}$ at $t=60$ min (Figs. 8 and 9d). The maximum pressure drop at the surface is approximately $40 \mathrm{hPa}$; this is 


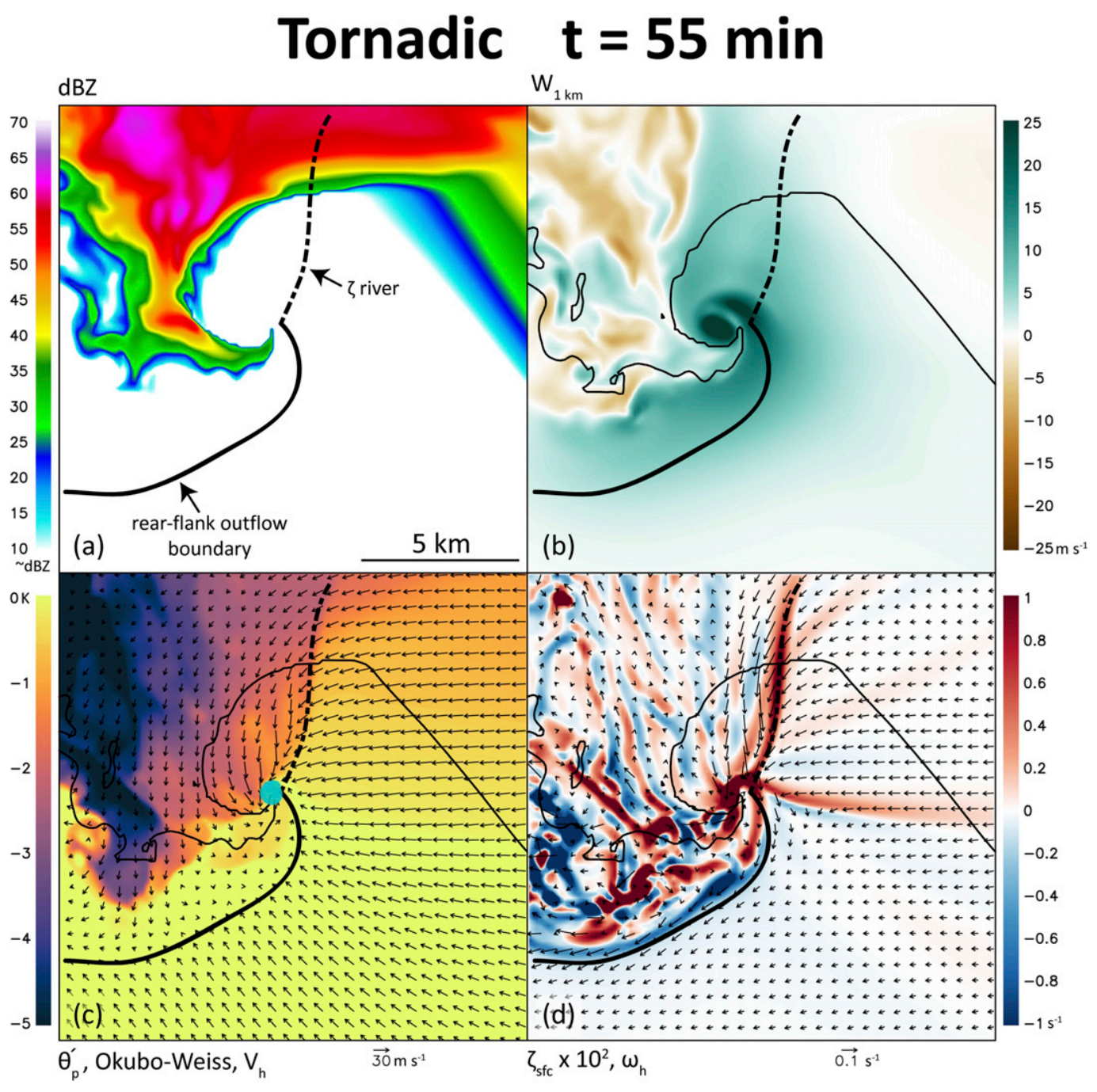

FIG. 7. As in Fig. 6, but for the tornadic VORTEX2 simulation at $t=55 \mathrm{~min}$.

associated with a maximum instantaneous $10-\mathrm{m}$ wind speed near $70 \mathrm{~m} \mathrm{~s}^{-1}$. At peak intensity, large values of the Okubo-Weiss parameter ${ }^{5}$ exceed $1 \mathrm{~km}$ in diameter (Fig. 8). The tornado forms at the intersection point between rear-flank outflow boundary and the vorticity river (Fig. 7c). Even though the low-level mesocyclone is strengthening aloft prior to tornadogenesis, vorticity at the surface develops independently of the circulation aloft and then rapidly builds upward within the lowest few hundred meters, eventually coupling with (and further intensifying) the low-level mesocyclone.

\footnotetext{
${ }^{5}$ The Okubo-Weiss parameter is defined by: $\mathrm{OW}=\zeta^{2}-D^{2}$, where the total deformation $\left[D=\left(D_{\text {stretching }}^{2}+D_{\text {shearing }}^{2}\right)^{1 / 2}\right]$ of the flow is subtracted from the vertical vorticity $(\zeta)$ to highlight the rotation of the fluid (Okubo 1970; Weiss 1991).
}

This process is consistent with the mode II tornadogenesis process from Trapp and Davies-Jones (1997), Davies-Jones et al. (2001), and Davies-Jones (2008) and has many similarities to the evolution of the lowlevel mesocyclone and resulting tornado in the Goshen County, Wyoming, supercell of 5 June 2009 [the most significant tornado in the V2 composite dataset; Markowski et al. (2012b); French et al. (2013)].

The tornado maintains a nearly constant stormrelative position during the most intense phase of the tornado (Fig. 8c). The vorticity river also remains in a quasi-steady north-south orientation for approximately 10 min during peak intensity (Fig. 8d). Beginning at $t=$ $60 \mathrm{~min}$, strong descent emerges toward the back of edge the hook echo (Fig. 8b), which is accompanied with positive density potential temperature perturbations at the surface embedded within the hook echo (Fig. 8c). By 


\section{Tornadic $t=60 \mathrm{~min}$}

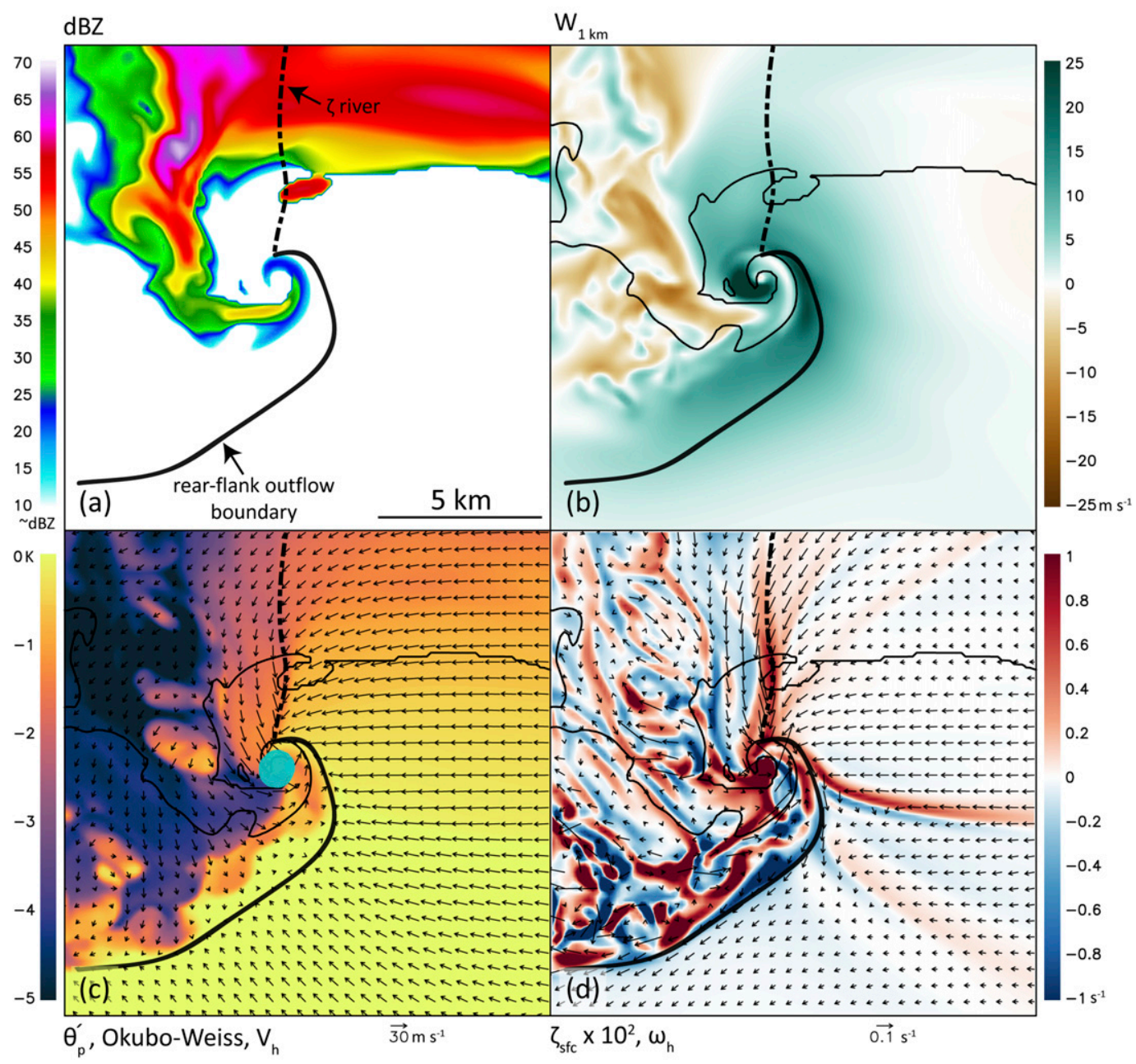

FIG. 8. As in Fig. 6, but for the tornadic supercell at $t=60 \mathrm{~min}$.

$t=65 \mathrm{~min}$ (not shown), the vorticity river becomes detached from the tornado following strong divergence near the tornado's axis of rotation, reducing the convergence of vertical vorticity (Rasmussen and Straka 2007). Downward velocities exceed $-20 \mathrm{~m} \mathrm{~s}^{-1}$ at $200 \mathrm{~m}$ above the surface. At this point, the tornado is displaced from the main updraft and begins rotating cyclonically around the mesocyclone, representing something like the rope-out phase of a tornado in nature. It briefly weakens at $t=72 \mathrm{~min}$ before strengthening again by $t=75 \mathrm{~min}$, by which time the tornado is well to the rear (more than $5 \mathrm{~km}$ ) of the outflow-inflow interface (Figs. 10a,c). The midlevel mesocyclone has begun to cycle with a new updraft developing downshear (Fig. 2i), while the old mesocyclone moves toward the rear of the storm (Figs. 10a,b). An anticyclonic tornado develops underneath a low-level mesoanticyclone within the supercell's flanking line [Fig. 10c; similar to Bluestein et al. (2016)] and lasts just over $10 \mathrm{~min}$, with a maximum $10-\mathrm{m}$ wind speed near $35 \mathrm{~m} \mathrm{~s}^{-1}$. Both tornadoes ultimately dissipate near $t=80 \mathrm{~min}$ following the emergence of colder outflow from the main precipitation region (not shown), with density potential temperature perturbation less than $-4 \mathrm{~K}$ in the hook echo, shunting the vortices away from the weakening low-level updraft (Figs. 9g,h).

The new updraft never intensifies to the degree the previous one did, and the supercell cycles twice more during the remainder of the simulation, remaining disorganized at low levels. Near the end of the 2-h simulation, the supercell once again begins to take on several features that were previously seen during the pretornadic phase documented above, including a vorticity river in the forward-flank precipitation and an intensifying low-level 


\section{Tornadic low-level mesocyclone}

(a) $t=40 \mathrm{~min}$

(c) $\mathrm{t}=50 \mathrm{~min}$

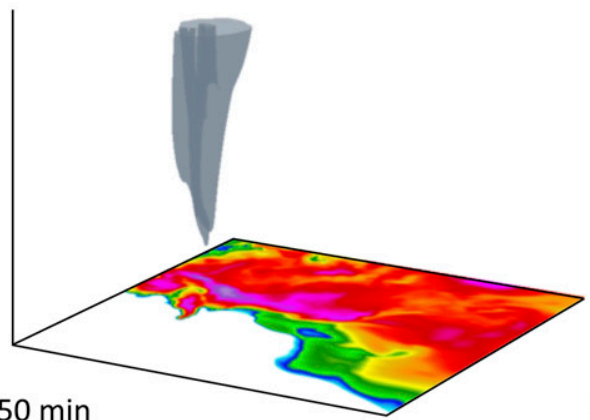

(d) $\mathrm{t}=55 \mathrm{~min}$

(b) $\mathrm{t}=45 \mathrm{~min}$
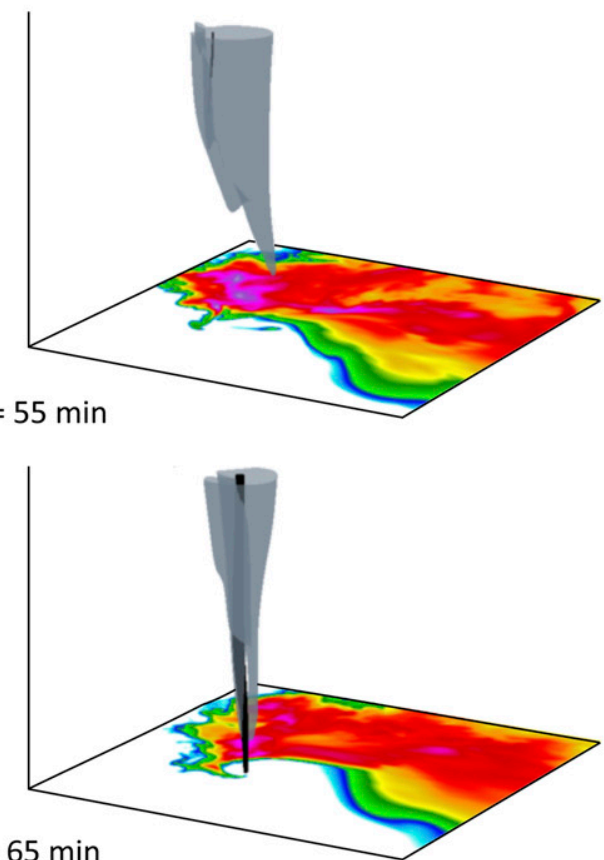

(e) $t=60 \mathrm{~min}$

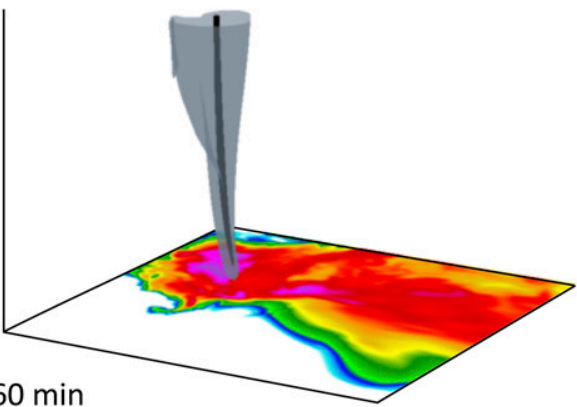

(f) $t=65 \mathrm{~min}$

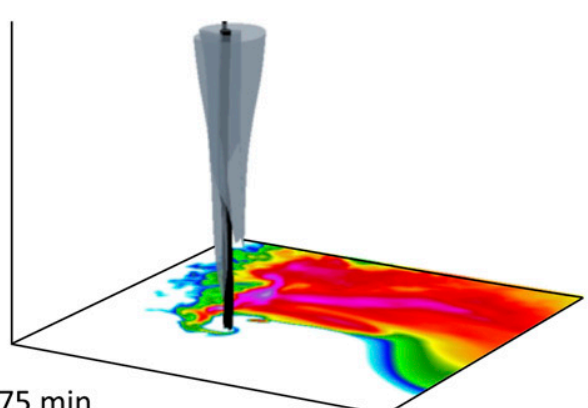

(g) $\mathrm{t}=75 \mathrm{~min}$

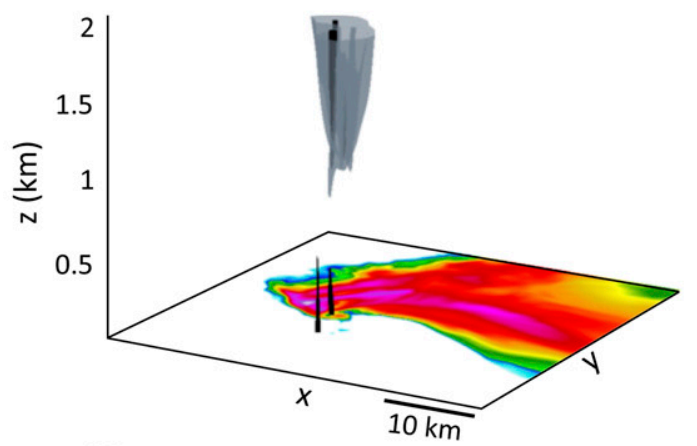

$20 \mathrm{~m} \mathrm{~s}^{-1}$ updraft isosurface $0.01 \mathrm{~s}^{-2}$ Okubo-Weiss isosurface

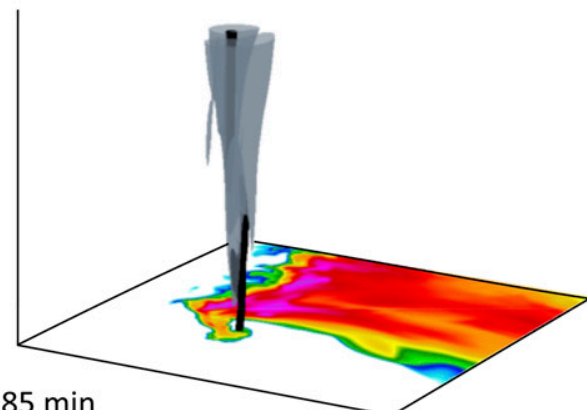

(h) $\mathrm{t}=85 \mathrm{~min}$

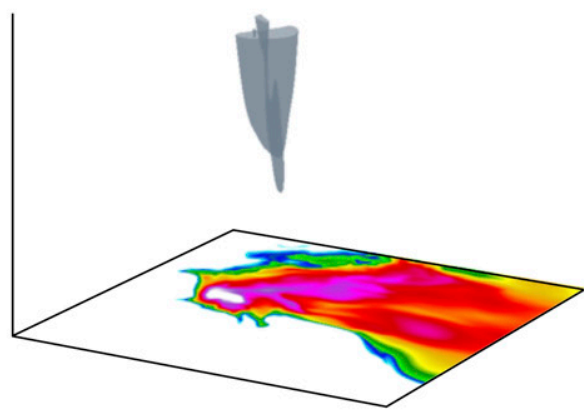

reflectivity $(\sim \mathrm{dBZ})$

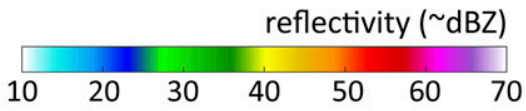

FIG. 9. Three-dimensional view of the low-level mesocyclone and tornado for the tornadic supercell. Shaded on the surface is the 500-m model-simulated base reflectivity $(\sim \mathrm{dBZ})$. Updraft and Okubo-Weiss isosurfaces of $20 \mathrm{~m} \mathrm{~s}^{-1}$ and $0.01 \mathrm{~s}^{-1}$ are shown light gray and black, respectively. See also an animated version of a similar figure (every $20 \mathrm{~s} ; 40$ times the normal speed) in the online supplemental material. 


\section{Tornadic $\mathbf{t}=75 \mathrm{~min}$}

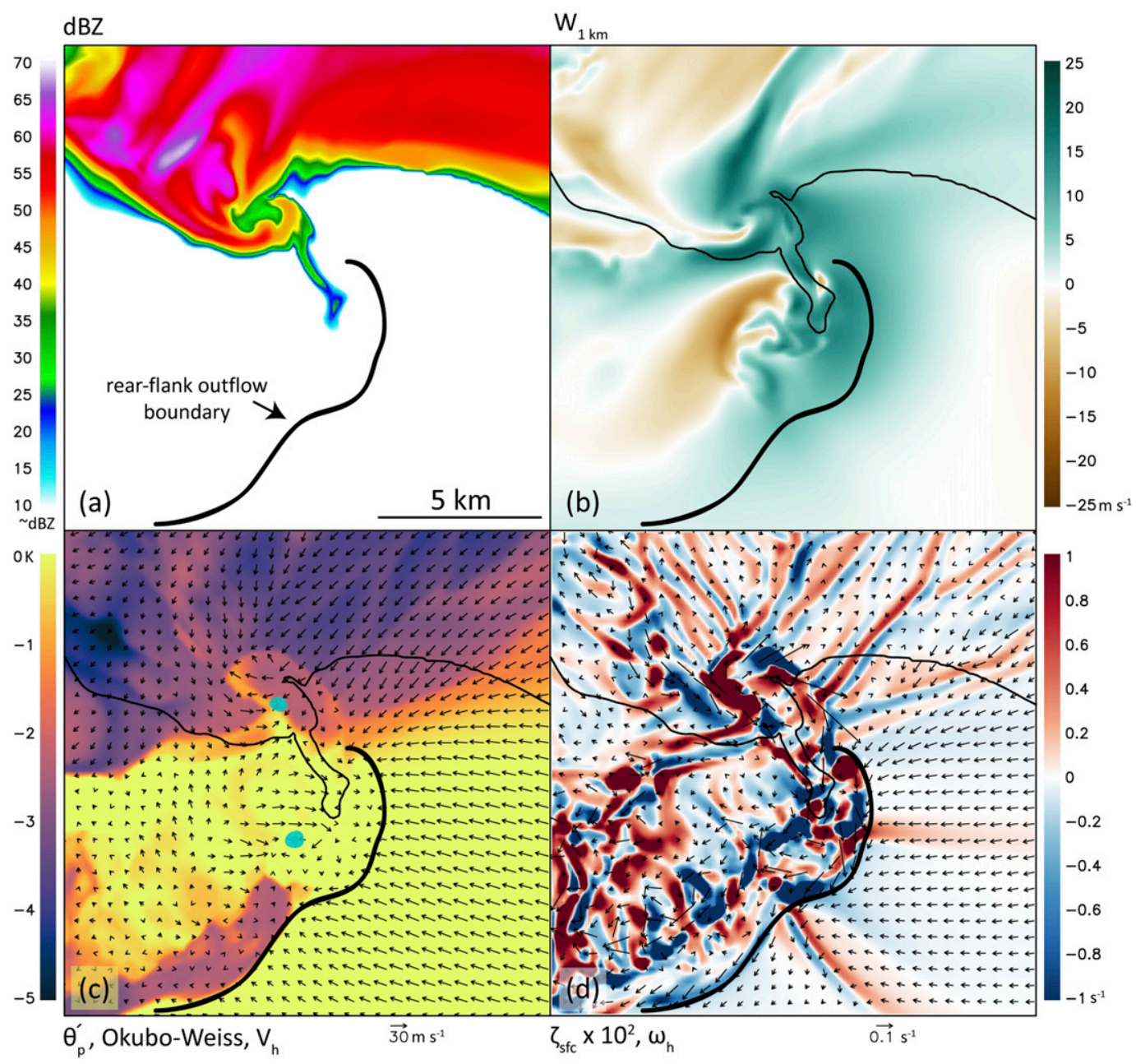

FIG. 10. As in Fig. 6, but for the tornadic supercell at $t=75 \mathrm{~min}$.

updraft. However, because we wished to focus on differences in the early evolution of the tornadic versus the nontornadic storms, the simulation was not extended beyond $2 \mathrm{~h}$.

\section{d. Nontornadic supercell}

Following initiation of the nontornadic simulation, the developing storm remains disorganized in the low levels until $t=50 \mathrm{~min}$ when supercellular features become more apparent (Fig. 3d). At $t=60 \mathrm{~min}$, the midlevel updraft is several kilometers ahead of the near-surface precipitation (Fig. 3f). While vertical velocities exceeding $15 \mathrm{~ms}^{-1}$ are present at $1 \mathrm{~km}$ (Fig. 11b), the low-level updraft is generally disorganized compared to the tornadic supercell's 1-km updraft, with pockets of descent present in the weak echo region (Fig. 11b). The main downdraft region to the northwest of the low-level updraft has begun to intensify, with velocities and density potential temperature perturbations less than $-20 \mathrm{~m} \mathrm{~s}^{-1}$ and $-5 \mathrm{~K}$, respectively (Figs. 11b,c). Widespread subtornadic surface vertical vorticity is already present within the rear-flank outflow, and as in the tornadic supercell, the vertical vorticity appears to emerge from vorticity rivers, which approach from the main precipitation core to the north (Figs. 11a,d). These vorticity rivers are again associated with localized confluence and a 1-2-K cross-river difference in density potential temperature perturbation. Many such vorticity rivers emanate from the pulsing main downdraft area throughout the supercell's most intense phase; however, none of these vorticity rivers acquire a quasi-steady stormrelative position in the way seen in the tornadic supercell (Figs. 11 and 12). This might shorten the time 


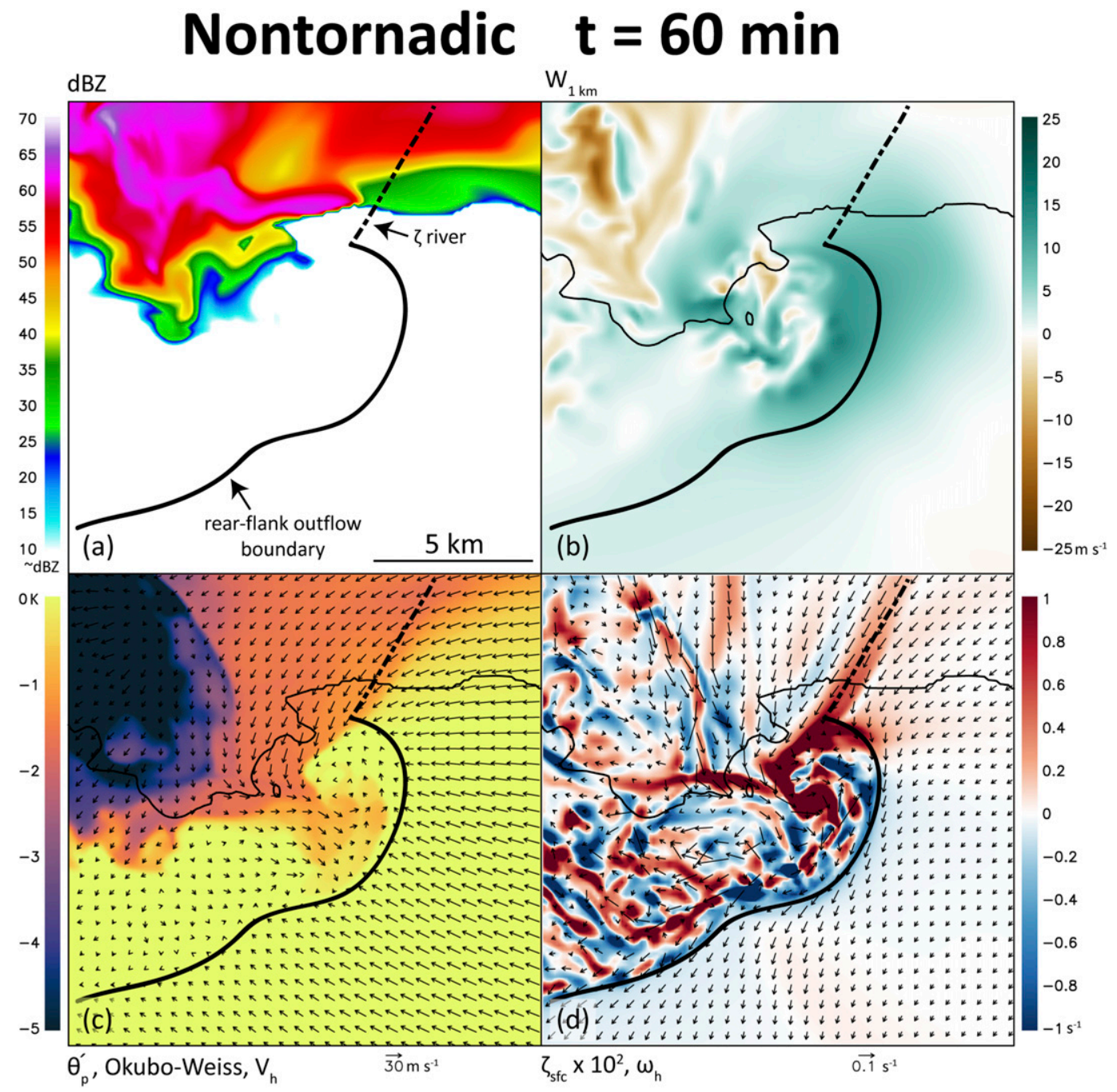

FIG. 11. As in Fig. 6, but for the nontornadic supercell at $t=60 \mathrm{~min}$. See also an animated version of this figure for the nontornadic supercell from $t=40$ to $90 \mathrm{~min}$ (every $60 \mathrm{~s}$; 100 times the normal speed) in the online supplemental material.

window within which the conditions for tornadogenesis coexist.

The supercell develops a hook echo by $t=65 \mathrm{~min}$ and produces a short-lived, shallow vortex near $t=70 \mathrm{~min}$ (Fig. 12). The near-surface vortex forms several kilometers west of the main low-level updraft (Figs. 12b,d), deeply embedded in the rear-flank outflow. The vortex briefly develops a peak intensity of surface vertical vorticity of $0.25 \mathrm{~s}^{-1}$, with a pressure drop of $5 \mathrm{hPa}$ and a maximum instantaneous $10-\mathrm{m}$ wind speed of near $27 \mathrm{~m} \mathrm{~s}^{-1}$. This represents the closest attempt at tornadogenesis during the nontornadic supercell. The broad vortex never contracts into a tornado and quickly dissipates into the rear-flank outflow. A few other brief spinups occur during the simulation along the rear-flank gust front and toward the back edge of the hook echo. Because of their location, these shallow spinups ( $<250 \mathrm{~m}$ in depth) were considered more like "gustnadoes" rather than failed tornadogenesis.

Preceding the vortex development, the low- and midlevel updrafts strengthen. However, due to the intensifying near-surface vortex, an "occlusion-like" downdraft forms. The occlusion downdraft (Klemp and Rotunno 1983) is a dynamical symptom of lower perturbation pressure at the surface than aloft, induced by increasing rotation near the surface. It is most often discussed within tornadic supercells (e.g., Markowski 2002), although Wakimoto and Cai (2000) showed that occlusion-like downdrafts can form in nontornadic supercells as well. In the nontornadic 


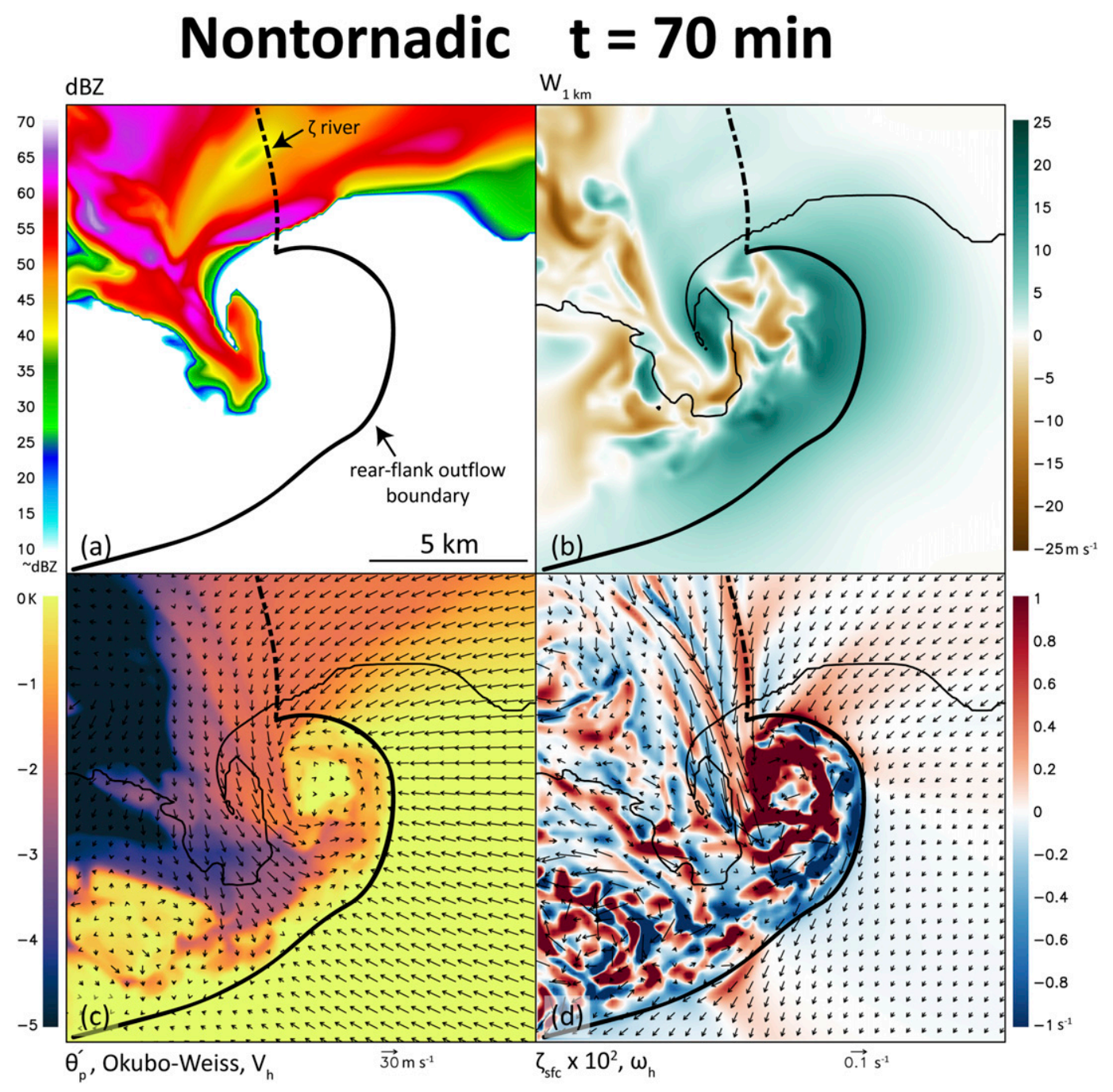

FIG. 12. As in Fig. 6, but for the nontornadic supercell at $t=70 \mathrm{~min}$.

supercell herein, this downdraft disrupts the developing vortex by replacing a concentrated area of convergence with divergence. The result is an annular region of vertical vorticity surrounding the downdraft (Fig. 12d), instead of a compact vortex, such as produced by the tornadic supercell. The broad, nearsurface circulation is even evident in the density potential temperature perturbation field ahead of the hook echo (Fig. 12c). Warmer temperature near the center of the circulation is associated with the dynamically induced downdraft and attendant adiabatic warming. The outflow air in the vicinity of the surface vortex is also not excessively cold $\left(\theta_{\rho}^{\prime}>-4 \mathrm{~K}\right.$; Fig. $\left.12 \mathrm{c}\right)$, in contrast to the nontornadic supercells analyzed by Markowski et al. (2002) and Grzych et al. (2007).

By $t=80 \mathrm{~min}$, the low-level updraft has taken on a horseshoe-shaped structure, with more precipitation present in the vicinity of the hook echo (Fig. 13). Despite density potential temperature perturbations of only -1 to $-3 \mathrm{~K}$ (Fig. 13c), the supercell appears to be "outflow dominated," exhibiting an increase in precipitation within the hook echo and a "bowed-out" narrow lowlevel updraft along the rear-flank outflow boundary (Fig. 13b). Ample surface vorticity is still present in the hook echo (Fig. 13d); however, it is displaced rearward from the strong low-level updraft (Fig. 13b), and thus it is not amplified by stretching. Meanwhile, dynamically induced downdrafts continue to form in the vicinity, preventing sustained convergence where subtornadic values of surface vertical vorticity are present (Fig. 13c). An explanation for the development of the dynamically induced downdrafts will be explored further in section 4 .

Following this period of activity, the low-level mesocyclone, which had been relatively persistent for the 


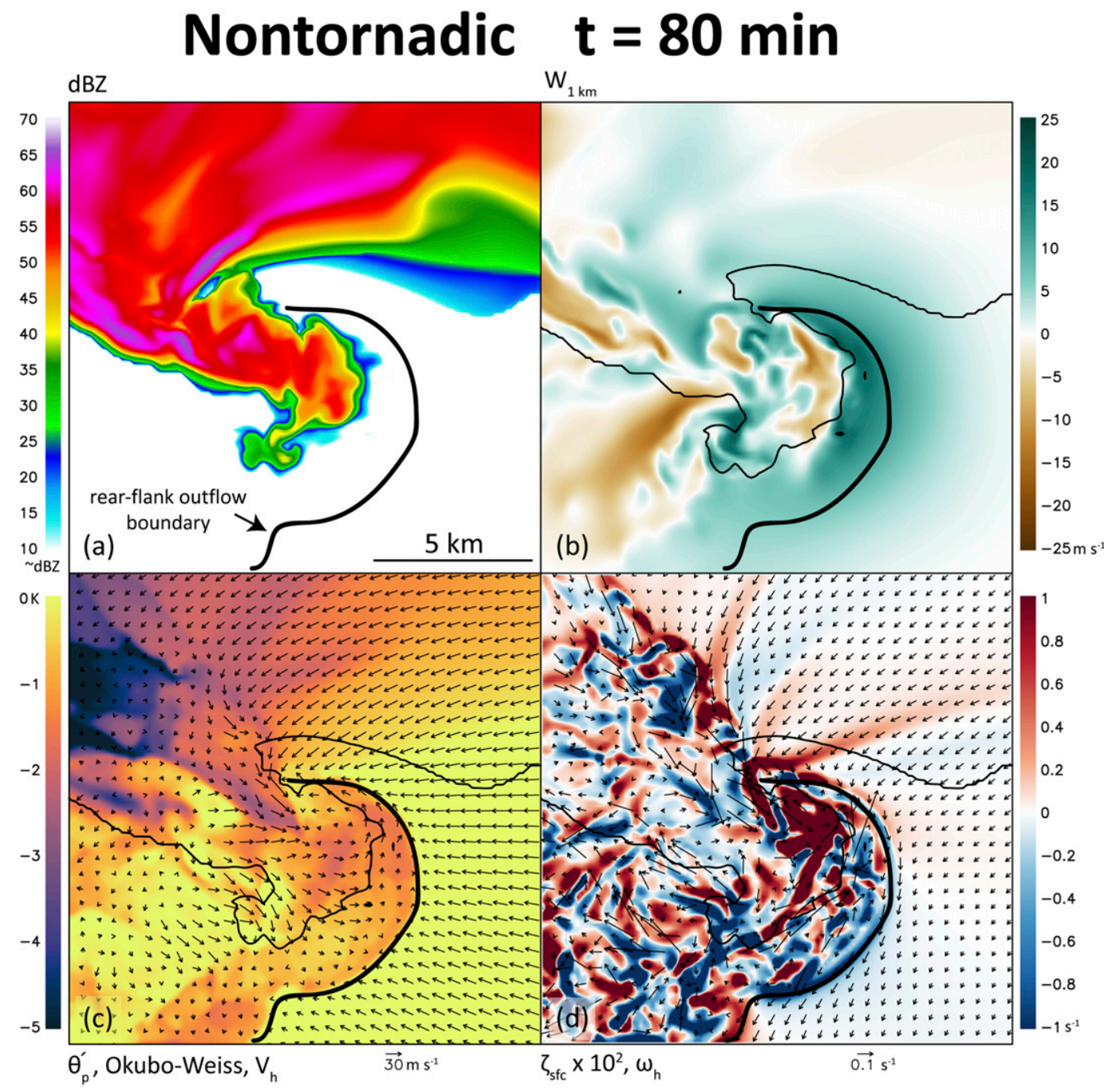

FIG. 13. As in Fig. 6, but for the nontornadic supercell at $t=80 \mathrm{~min}$.

prior $30 \mathrm{~min}$, occludes toward the rear of the storm. The supercell goes onto cycle once more during the remainder of the simulation, but never again comes close to producing a tornado.

\section{Storm-scale differences contributing to tornadogenesis or tornadogenesis failure}

To further illustrate differences between the two supercells, time composites centered on the midlevel updraft were created for the $15 \mathrm{~min}$ during the failed genesis in the nontornadic supercell and the $15 \mathrm{~min}$ leading up to the most intense near-surface vortex in the tornadic supercell. In the nontornadic supercell, the main updraft at $1 \mathrm{~km}$ AGL is focused along the rear-flank outflow boundary and overall weaker (Figs. 14a,e). The tornadic supercell has a stronger $1-\mathrm{km}$ updraft immediately adjacent to the hook echo (Fig. 14b). The low-level updraft is vertically collocated underneath the midlevel updraft in both supercells (not shown), a configuration thought to be favorable for tornadogenesis (French et al. 2008). Both simulations produce large values of surface vorticity; however, the nontornadic supercell produces an overabundance of surface vorticity behind the updraft, nearer to the precipitation (Figs. 14c,d). Without being superimposed under the low-level updraft, the surface vorticity that does develop in the nontornadic supercell is not stretched into a deep, intense vortex. Instead a persistent downdraft signal is present near the surface vorticity in the nontornadic supercell (Figs. 14a,c), likely a dynamical response to the rotation at the surface (shown later). Also, a stronger signal for descent is present in the rear of the storm (Fig. 14a), accompanied by higher concentrations of 


\section{Time composite}

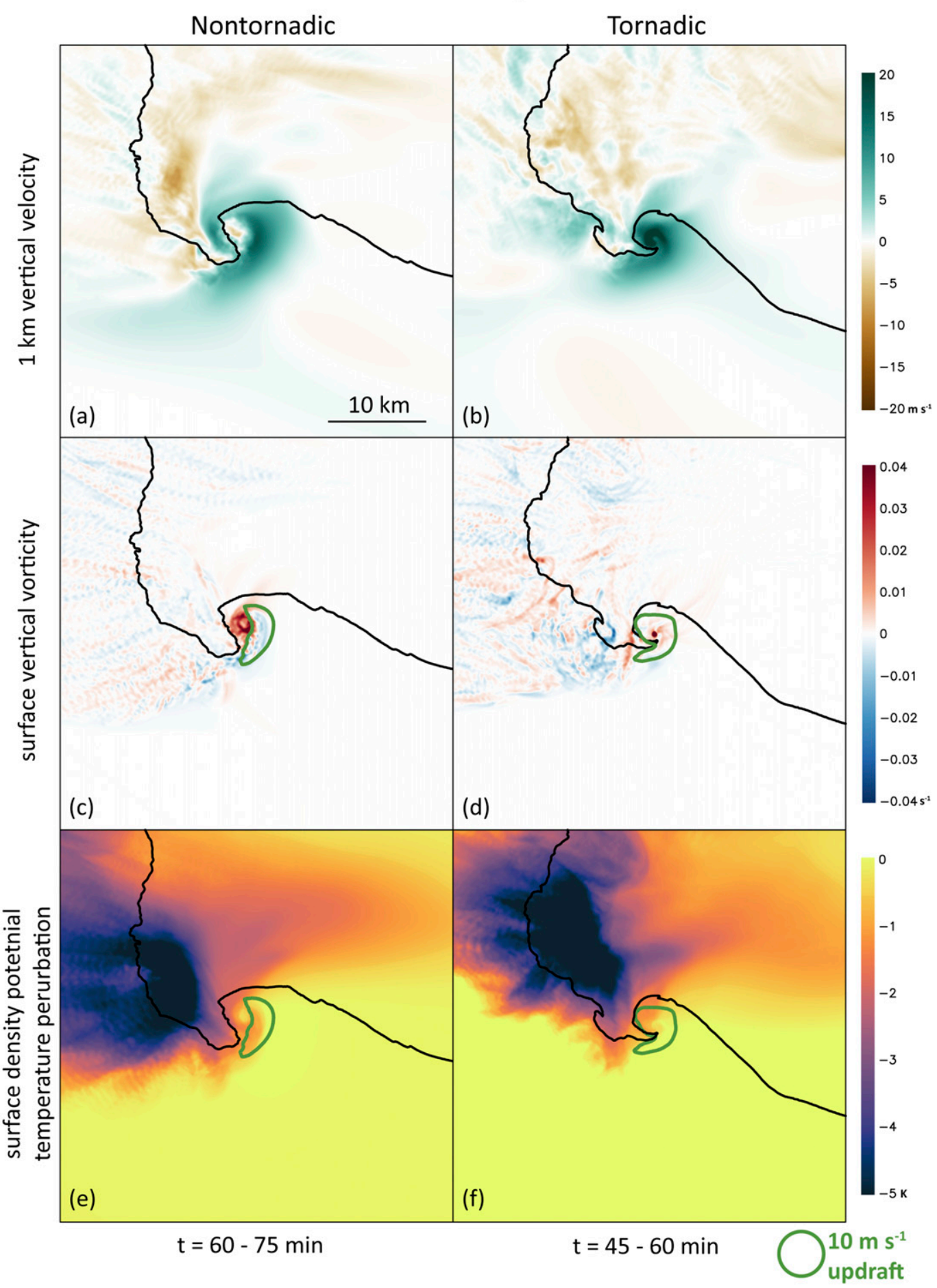

FIG. 14. Time composite plot showing the 15-min average spatial (a),(b) 1-km vertical velocity field ( $\mathrm{m} \mathrm{s}^{-1}$ ); (c),(d) 10-m vertical vorticity field $\left(\mathrm{s}^{-1}\right)$; and (e),(f) 10-m density potential temperature deficit (K) for (left) the nontornadic supercell and (right) the tornadic supercell. The $10 \mathrm{~m} \mathrm{~s}^{-1}$ vertical velocity contour (green) at $1 \mathrm{~km}$ AGL and the averaged 10-dBZ model-simulated reflectivity at $500 \mathrm{~m}$ AGL (black contour) are shown for reference. 
Nontornadic: Failed tornadogenesis trajectories

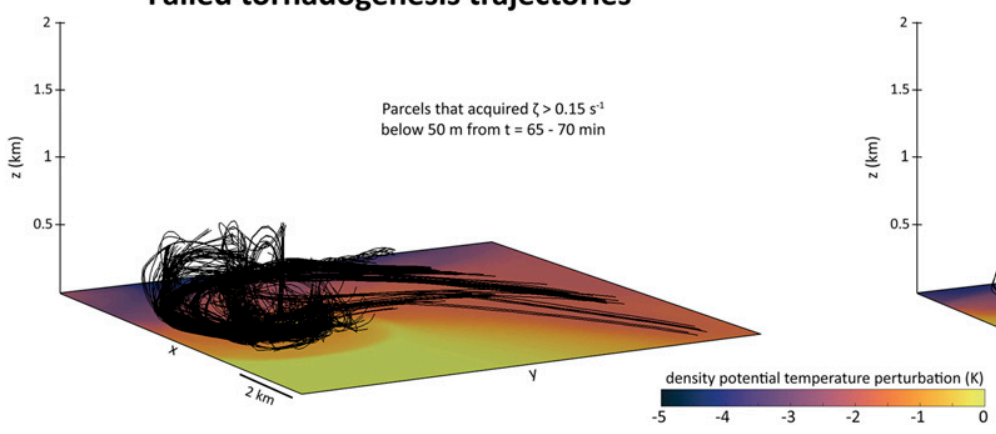

Tornadic: Tornadogenesis trajectories

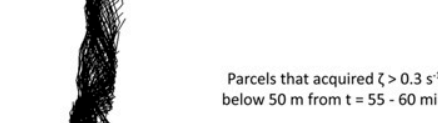

FIG. 15. Three-dimensional view of trajectories that acquired large near-surface vertical vorticity between the lowest three vertical grid points (10-50 m AGL) in both the (left) nontornadic supercell and (right) tornadic supercell during the final 5 min of the trajectory integration period. Shaded on the surface is the average 10-m density potential temperature perturbation (K) during the same time period. A higher vertical vorticity threshold was applied in the tornadic supercell solely for clarity purposes.

precipitation mixing ratio within the hook echo of the nontornadic supercell (not shown). The outflow temperature in the rear flank is not noticeably different between the simulations (Figs. 14e,f). On average, both storms have peak density potential temperature perturbations near $-7 \mathrm{~K}$ during the 15 -min time composite. The forward-flank baroclinic gradient north of the lowlevel updraft is slightly stronger $\left(\sim 1 \mathrm{~K} \mathrm{~km}^{-1}\right)$ in the tornadic supercell (Figs. 14e,f). The orientation of the storm-relative cold pool is slightly shifted, likely because ambient low-level winds are from the east in the nontornadic case and from the southeast in the tornadic case. Although both cold pools have similar potential temperature deficits, the outflow boundary in the nontornadic supercell extends farther ahead of the rear-flank precipitation, and the low-level updraft appears bowed out along the rear-flank outflow boundary (Figs. 14e,f).

To visualize the tornadogenesis failure mode and successful tornadogenesis process in the respective supercells, parcels were launched in a $20 \times 20 \mathrm{~km}^{2}$ box surrounding the developing surface vorticity, spaced every $62.5 \mathrm{~m}$ in the horizontal and every $20 \mathrm{~m}$ in the lowest $2 \mathrm{~km} \mathrm{AGL}$ at $t=50(t=60) \mathrm{min}$ in the tornadic (nontornadic) supercell. In total, nearly 13 million parcels were integrated forward on each model time step $(0.6 \mathrm{~s})$ for $10 \mathrm{~min}$, with output saved every $10 \mathrm{~s}$. We used this approach instead of targeted backward trajectories because, in highly curved, confluent flow regimes, Dahl et al. (2012) showed that forward trajectories with small time steps are more accurate than backward trajectories computed from model history files.

Parcels that acquired vertical vorticity near the surface in the nontornadic supercell fail to be lifted and stretched into the overlying storm (Fig. 15a). The few parcels that did begin to rise experienced abrupt descent back toward the surface. Since the outflow region is not particularly cold relative to the ambient inflow air, the failure of parcels to be lifted into the storm is most likely due to the lack of a broad, consistent area of dynamic lifting (shown later). Additionally, cross sections through developing vortices show a quick transition from an "in-up" to a "down-out" circulation (not shown), as in the nontornadic supercells analyzed by Markowski et al. (2011). No such issue exists in the tornadic supercell; parcels that acquired large surface vertical vorticity traversed down the vorticity river, within an east-west baroclinic gradient, before curling cyclonically into the tornado near the ground and then swiftly rising into the low-level mesocyclone at $1 \mathrm{~km}$ AGL (Fig. 15b). Since the tornado is on the eastern edge of the low-level updraft (Figs. 7b,c), some of the parcels rose briefly to the west before descending back down toward the surface as they curled into the tornado. The rapid ascent of the parcels into the mesocyclone indicates a coupling between the surface circulation and the overlying updraft, a configuration highly supportive of vortex stretching. The opposite is true in the nontornadic supercell; the surface circulation appears decoupled from the low-level ( $\sim 1 \mathrm{~km} \mathrm{AGL})$ updraft, leading to a disruption of vortex stretching and thus tornadogenesis failure (Trapp 1999; Markowski et al. 2011).

The pretornadic intensification of the low-level updraft in the tornadic supercell is caused by an increase in the dynamic vertical perturbation pressure gradient acceleration. ${ }^{6}$ The vertical accelerations at low-levels in

\footnotetext{
${ }^{6}$ Our decomposition of the perturbation pressure components and the corresponding vertical accelerations are described in section $3 b$ of Coffer and Parker (2015).
} 

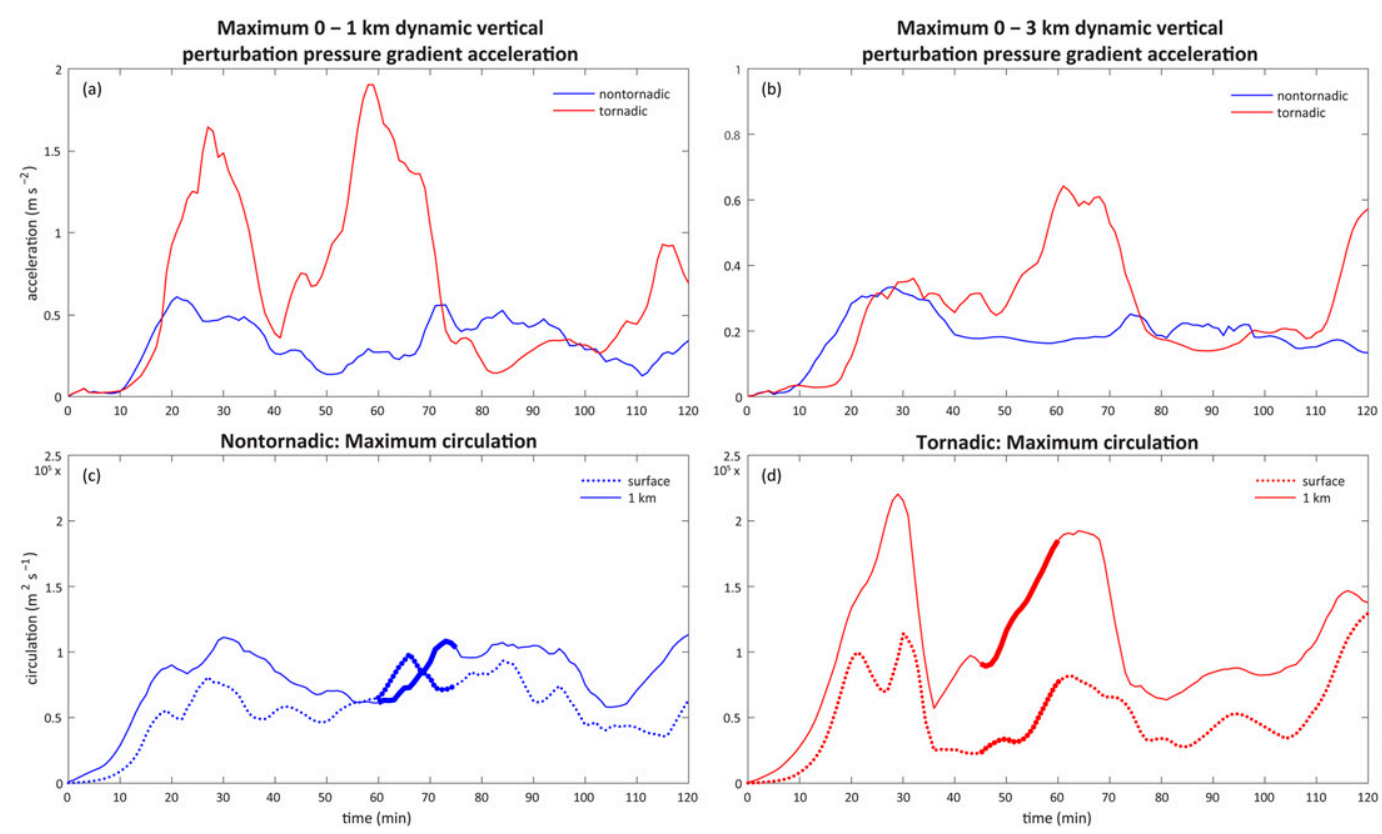

FIG. 16. Time series comparing the dynamic vertical perturbation pressure gradient acceleration (VPPGA; $\mathrm{m} \mathrm{s}^{-2}$ ) and circulation $\left(\mathrm{m}^{2} \mathrm{~s}^{-1}\right)$ for both the nontornadic (blue) and tornadic (red) supercells in a $50 \times 50 \mathrm{~km}^{2}$ box following the supercell's mesocyclone. (top) The maximum acceleration value in both the (a) 0-1- and (b) 0-3-km layers. (bottom) The maximum circulation computed around a 1-km-radius horizontal ring centered at each grid point at the surface (dotted line) and $1 \mathrm{~km}$ (solid line) for the (c) nontornadic and (d) tornadic supercells. The bolded time periods represent the 15-min time composite shown in Fig. 14. A five-point smoother was used on each time series to account for jumps while tracking the supercell's mesocyclone.

these simulations is dominated by nonlinear dynamic pressure perturbations caused by rotation, deformation, and/or divergence. The low-level dynamic vertical accelerations increase by $300 \%$ in the $15 \mathrm{~min}$ prior to tornadogenesis $(t=40-55 \mathrm{~min}$; Fig. 16a). The apex in $0-1-\mathrm{km}$ dynamic vertical perturbation pressure gradient acceleration occurs at the same time the tornado peaks in intensity. The substantial increases in upward dynamic vertical perturbation pressure gradient acceleration are not simply a symptom of the developing tornado but rather the catalyst. Strong rotation at the surface, as in a tornado, would instead be associated with a downwarddirected dynamic vertical perturbation pressure gradient acceleration (Lewellen et al. 2000; Nolan 2013; Rotunno 2013). The 0-3-km dynamic vertical perturbation pressure gradient acceleration also shows large increases but not until $10 \mathrm{~min}$ later $(t=50 \mathrm{~min}$; Fig. 16b). The nontornadic supercell has much weaker increases in the $0-1-$ and $0-3-\mathrm{km}$ dynamic vertical perturbation pressure gradient acceleration during its failed genesis period ( $t=60-75 \mathrm{~min}$; Figs. 16a,b), and these accelerations are not spatially superimposed over the surface subtornadic vertical vorticity for a prolonged period of time (Figs. 17a-c).

The main, persistent area of lifting in the nontornadic supercell is several kilometers ahead of where the surface vorticity resides (cf. Figs. $14 \mathrm{c}$ and $17 \mathrm{a}-\mathrm{c}$ ). Behind this, the dynamic acceleration is strikingly disorganized as both positive and negative areas of acceleration frequently form and dissipate (Figs. 17a-c). Without a persistent area of upward lifting, the surface vorticity that does develop in the nontornadic supercell is not likely to be contracted into a tornado. In contrast, the tornadic supercell has a sustained area of upward accelerations encompassing the entire weak echo region where the tornado will eventually form (Figs. 17d,e). Interestingly, at the time the tornado finally dissipates (Fig. 17f), the acceleration field looks as disorganized as the nontornadic storm did throughout its entire life cycle.

It is well known that rotation is associated with locally negative dynamic pressure perturbations (Markowski and Richardson 2010, 28-30). Therefore, it is insightful to compare circulation ${ }^{7}$ tendencies between the supercells, as circulation is qualitatively related to dynamic pressure minima in flow regimes where the rotation

\footnotetext{
${ }^{7}$ Circulation $C$ is defined as the area $A$ sum of vertical vorticity $\zeta$ (i.e., $11 \iint_{A} \zeta d A$ ). Herein, circulation was computed within a $1-\mathrm{km}$ radius horizontal ring centered at each grid point within the domain's constant grid spacing inner mesh.
} 


\section{0 - 1 km dynamic vertical perturbation pressure gradient acceleration}

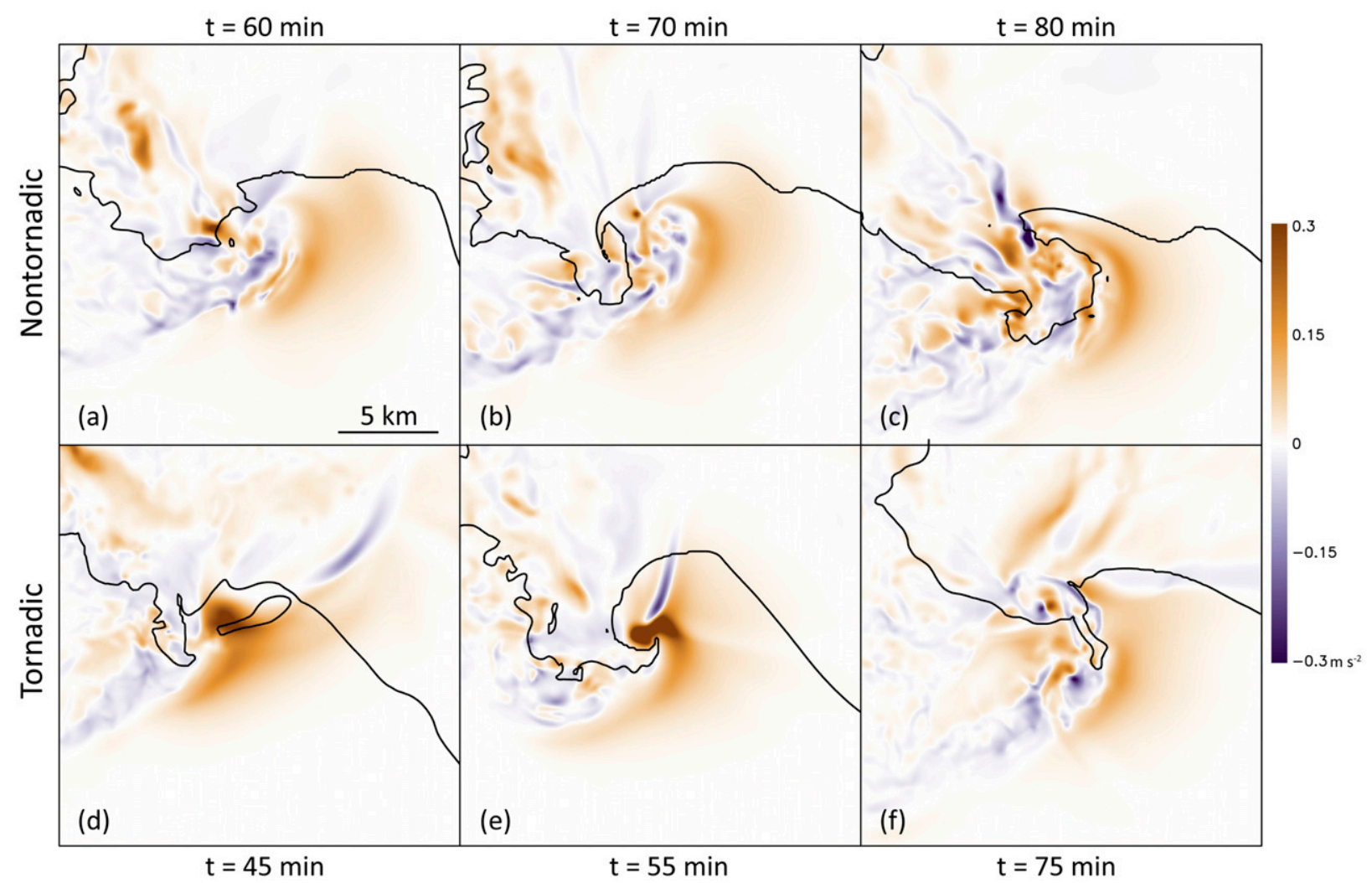

FIG. 17. Horizontal cross sections of $0-1-\mathrm{km}$ dynamic vertical perturbation pressure gradient acceleration $\left(\mathrm{m} \mathrm{s}^{-2} ; \mathrm{shaded}\right)$ and the $10-\mathrm{dB} Z$ reflectivity at $500 \mathrm{~m}$ AGL (black contour) from the (a)-(c) nontornadic and (d)-(f) tornadic VORTEX2 simulations.

predominates (e.g., Figs. 18 and 19). It is noteworthy that the surface circulation in the tornadic case is very similar to that in the nontornadic case during the key time period (Figs. 16c,d). This implies that the nontornadic supercell at least has the potential to be tornadic if air parcels could be converged into a sufficient radius. However, in the tornadic supercell, the $1-\mathrm{km}$ circulation is much stronger than the surface circulation (Fig. 16d), whereas it is similar or weaker in the nontornadic supercell (Fig. 16c). The differences in circulation appear to directly impact the dynamic accelerations shown in Fig. 16, via the vertical structures that we explain next.

The two supercells have contrasting orientations of cyclonic-anticyclonic circulation at $1 \mathrm{~km}$ AGL (cf. Figs. 18d-f and 19d-f). The 1-km circulation in the nontornadic storm is found primarily behind the main updraft region and is associated with a highly deformational wind field, rather than a closed rotational circulation (Figs. 18d-f). Deformation is associated with locally positive dynamic pressure perturbations (Markowski and Richardson 2010, 28-30). Therefore, directly above the center of surface circulation there are positive nonlinear dynamic pressure perturbations at $1 \mathrm{~km}$ in the nontornadic supercell (Figs. 18e,f). When paired with the pressure minimum at the surface subtornadic vortex (Figs. 18a-c), this leads to a dearth of vertical vorticity stretching at the surface because the dynamic vertical pressure perturbation gradient acceleration is negligible, or even downward (Figs. 17a-c). The lack of persistent dynamic lifting, encapsulated by surface circulation that exceeds the circulation at $1 \mathrm{~km}$ AGL (Fig. 16c), supports the assertion in section 3d that dynamically induced downdrafts disrupted the vortex spinup in the nontornadic supercell, ultimately leading to a failed tornadogenesis attempt. Similar configurations of cyclonic-anticyclonic vorticity couplets have been reported in observed nontornadic supercells 


\section{Circulation: Nontornadic}

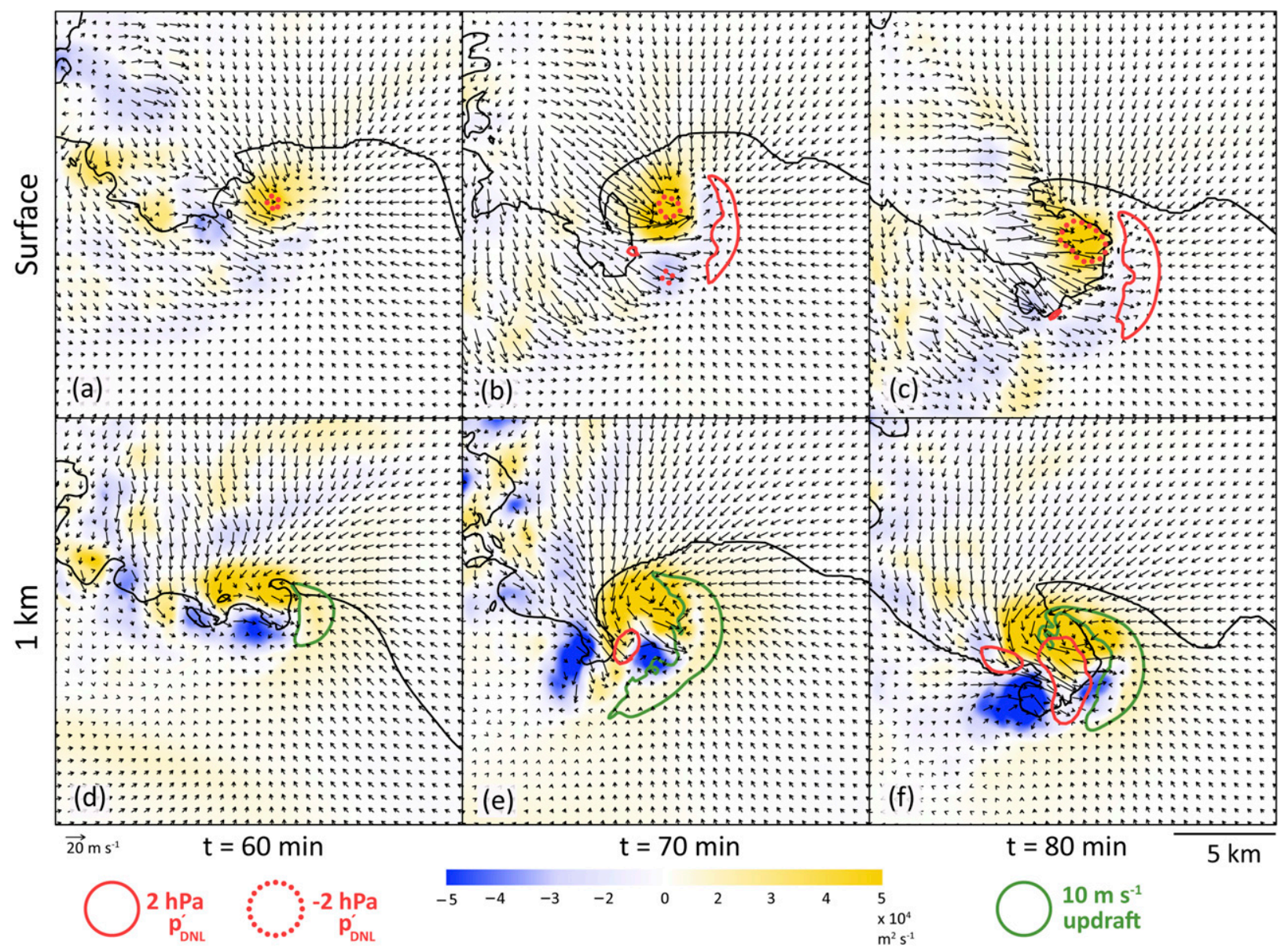

FIG. 18. Horizontal cross sections of circulation $\left(\mathrm{m}^{2} \mathrm{~s}^{-1}\right.$; shaded) computed around a 1-km-radius horizontal ring centered at each grid point at (a)-(c) the surface and (d)-(f) $1 \mathrm{~km}$ for the nontornadic supercell. Also shown is the 10 -dB $Z$ reflectivity contour (black) at $500 \mathrm{~m}$ AGL, the $10 \mathrm{~m} \mathrm{~s}^{-1}$ vertical velocity contour (green) at $1 \mathrm{~km} \mathrm{AGL}$, and the \pm 2 -hPa nonlinear dynamic pressure perturbation $\left(p_{\mathrm{DNL}}^{\prime}\right)$ contour (red, if present) at $1 \mathrm{~km}$ AGL. For clarity, pressure perturbations are only plotted near hook and weak echo regions of the supercell. Vectors represent the perturbation horizontal velocity, plotting every fifth vector.

(Bluestein and Gaddy 2001; Markowski 2008), and Beck et al. (2006) found an analogous disassociation between the updraft and circulation of the mesocyclone at $1 \mathrm{~km}$ AGL, in addition to a large deformation component to the flow, in a nontornadic supercell with predominately near-surface crosswise horizontal vorticity.

In contrast, in the tornadic supercell, a closed 1-km circulation exists within the main updraft (Figs. 19d-f). The closed circulation leads to negative nonlinear dynamic pressure perturbations in the mesocyclone (Figs. 19d-f) and results in a much more favorable setup for upward dynamic accelerations (Figs. 17d-f). The main, cyclonic tornado develops directly underneath the vertically stacked low-level mesocyclone (Figs. 19b,e). The strong circulation aloft, and the associated areas of lower nonlinear dynamic pressure perturbations in the tornadic supercell (e.g., at $1 \mathrm{~km} \mathrm{AGL),} \mathrm{provide} \mathrm{a} \mathrm{broad,}$ consistent area of upward dynamic acceleration during the time period when vertical vorticity is intensifying at the surface.

The differences in the orientation of the 1-km circulation couplets in the nontornadic and tornadic supercells likely result from the varying flux of streamwise horizontal vorticity into the nontornadic versus tornadic updrafts. As described by Davies-Jones (1984), the tilting and advection of crosswise horizontal vorticity by the storm-relative wind engenders positive-negative circulation couplets on either side of the updraft maximum, whereas streamwise horizontal vorticity results in the positive circulation component being advected preferentially into the updraft. To quantitatively evaluate the bulk characteristics of the low-level mesocyclone 


\section{Circulation: Tornadic}

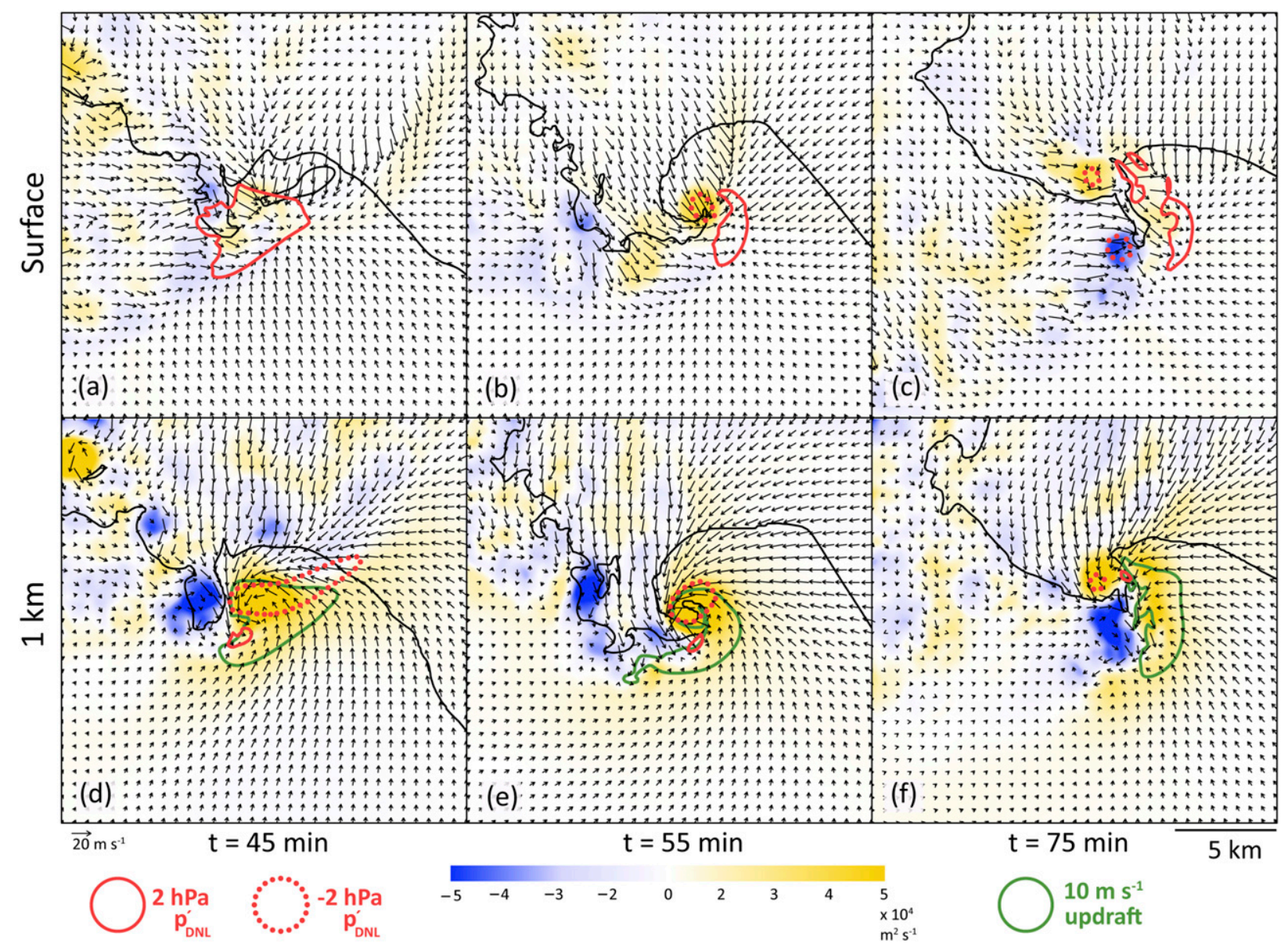

FIG. 19. As in Fig. 18, but for the tornadic VORTEX2 simulation.

in each supercell, another set of parcels was launched at every horizontal grid point and every $20 \mathrm{~m}$ vertically in the lowest $2 \mathrm{~km}$ AGL of the inflow region (yielding approximately 10 million parcels integrated forward) at 10 min prior to the time period composited in Fig. 14 . Trajectories were filtered to isolate the 500 parcels that acquired the largest vertical velocity (with at least $0.01 \mathrm{~s}^{-1}$ of vertical vorticity) within $50 \mathrm{~m}$ of $1 \mathrm{~km}$ AGL. All parcels that entered the low-level mesocyclone originated below $300 \mathrm{~m}$ AGL. The horizontal vorticity in this nearsurface layer was predominately crosswise (streamwise) in the nontornadic (tornadic) environment (Fig. 20). Not surprisingly, these low-level mesocyclone parcels also had a much higher vertical velocity and obtained much larger values of vertical vorticity in the tornadic supercell (Fig. 20). This suggests that not only does larger streamwise vorticity lead to a more intense lowlevel mesocyclone [as suggested by Markowski et al. (2012b); Markowski and Richardson (2014); Coffer and Parker (2015)], but predominately crosswise vorticity in the boundary layer leads to a less favorable configuration of the low-level mesocyclone for tornadogenesis (cf. Figs. 18 and 19).

\section{Idealized updrafts in VORTEX2 wind profiles}

It is clear that the composite VORTEX2 environments contain sufficient information to "correctly" simulate supercells with nontornadic and tornadic characteristics. Additionally, the failure mode for tornadogenesis in the nontornadic supercell appears to be due to a disorganized low-level mesocyclone and thus a lack of convergence and stretching of subtornadic surface vorticity into a tornado. However, direct attribution of this process to the environmental profiles is difficult to completely ascertain from the full-physics simulations. In section 4, we inferred that the nearsurface crosswise horizontal vorticity in the nontornadic 


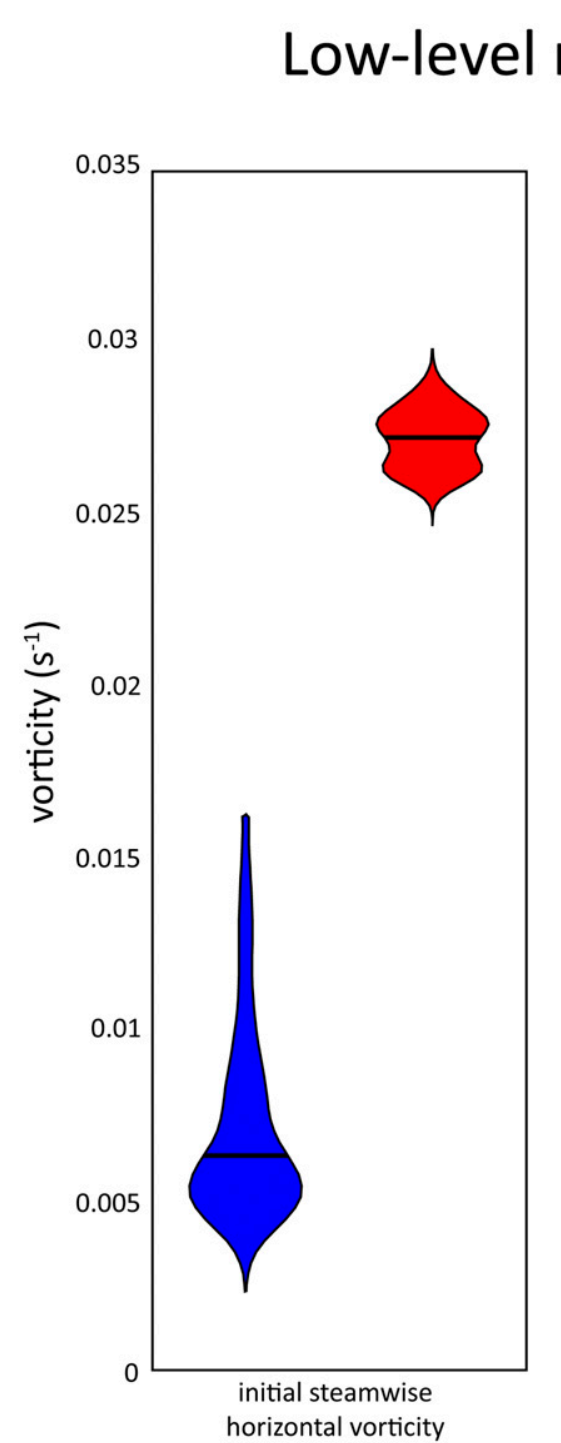

\section{mesocyclone parcel characteristics}
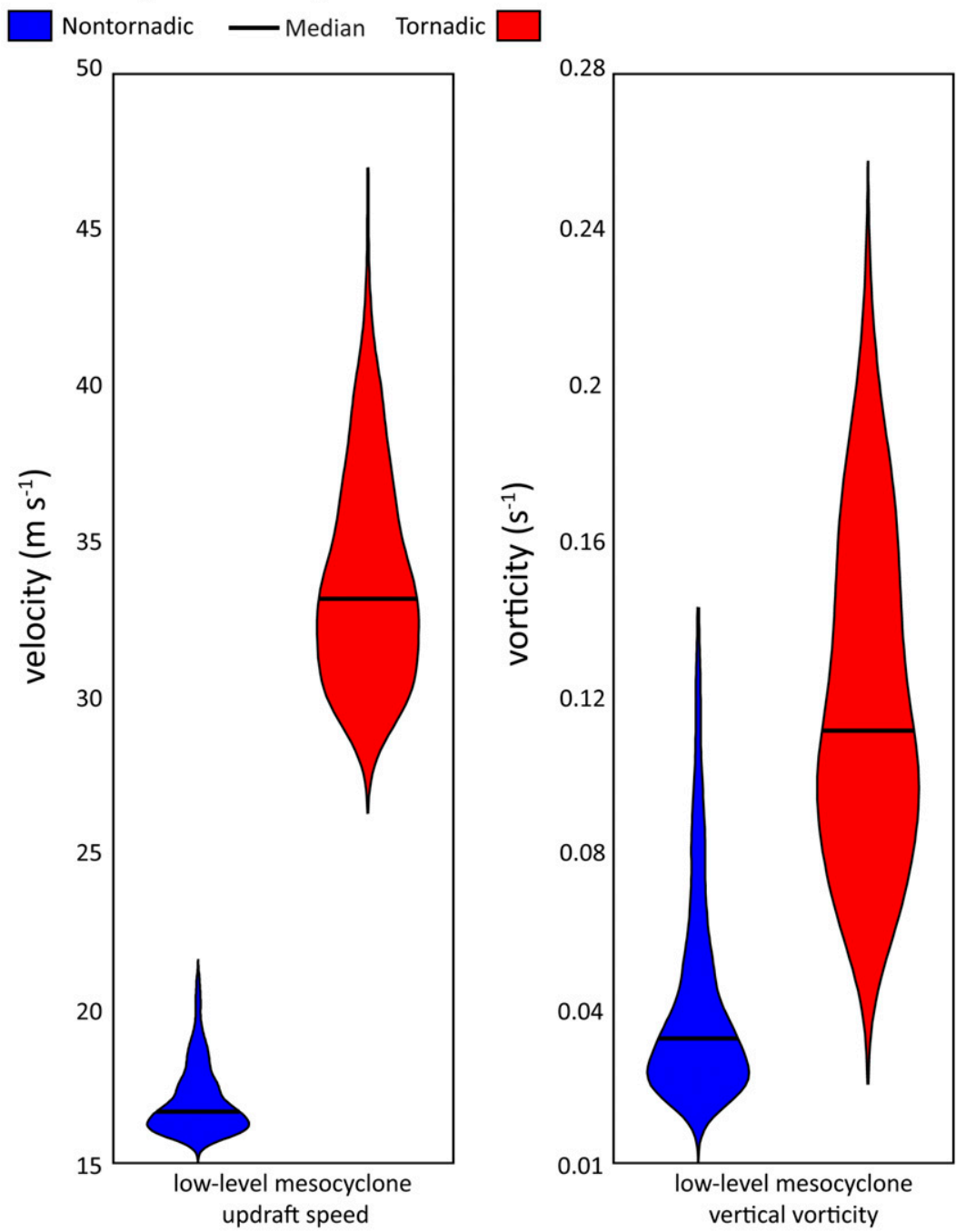

FIG. 20. Smoothed kernel density estimation violin plot of low-level mesocyclone parcel characteristics from the VORTEX2 simulations for the 500 parcels that acquired the highest vertical velocity, with vertical vorticity at least $0.01 \mathrm{~s}^{-1}$, between 950 and $1050 \mathrm{~m} \mathrm{AGL}$. (from left to right) Initial streamwise horizontal vorticity $\left(\mathrm{s}^{-1}\right)$, vertical velocity $\left(\mathrm{m} \mathrm{s}^{-1}\right)$, and vertical vorticity $\left(\mathrm{s}^{-1}\right)$ for the nontornadic (blue) and tornadic (red) VORTEX2 simulations. The black line represents the median of the distribution.

environment, when tilted by the supercell's updraft, yields an unfavorable couplet of cyclonic and anticyclonic circulation at $1 \mathrm{~km}$ AGL. Neither member of the couplet is collocated with the low-level updraft, and a deformational pressure maximum overlies the center of surface vorticity. This might explain the less steady updraft in the nontornadic supercell, as well as its displacement from the zone of large surface vorticity. To isolate the direct effect of differences in the VORTEX2 lower-tropospheric wind profiles upon developing updrafts, additional simpler simulations were conducted.
In a similar manner to Markowski and Richardson (2014), a stationary, spheroidal heat source is implemented by adding a heating tendency to the model's potential temperature equation. This forcing has a peak amplitude of $0.05 \mathrm{~K} \mathrm{~s}^{-1}$, varies as the cosine of distance from its center at $5.25 \mathrm{~km}$ above the origin, and has a horizontal and vertical radii of 3 and $4.75 \mathrm{~km}$, respectively. The size, shape, and magnitude of the heating tendency emulates the latent heat release in a supercell's updraft. These simulations are run dry with a grid spacing of $500 \mathrm{~m}$ on a domain of $100 \times 100 \times 18 \mathrm{~km}^{3}$. The environmental thermodynamic profile has a constant 


\section{Low-level circulation: Idealized simulations}

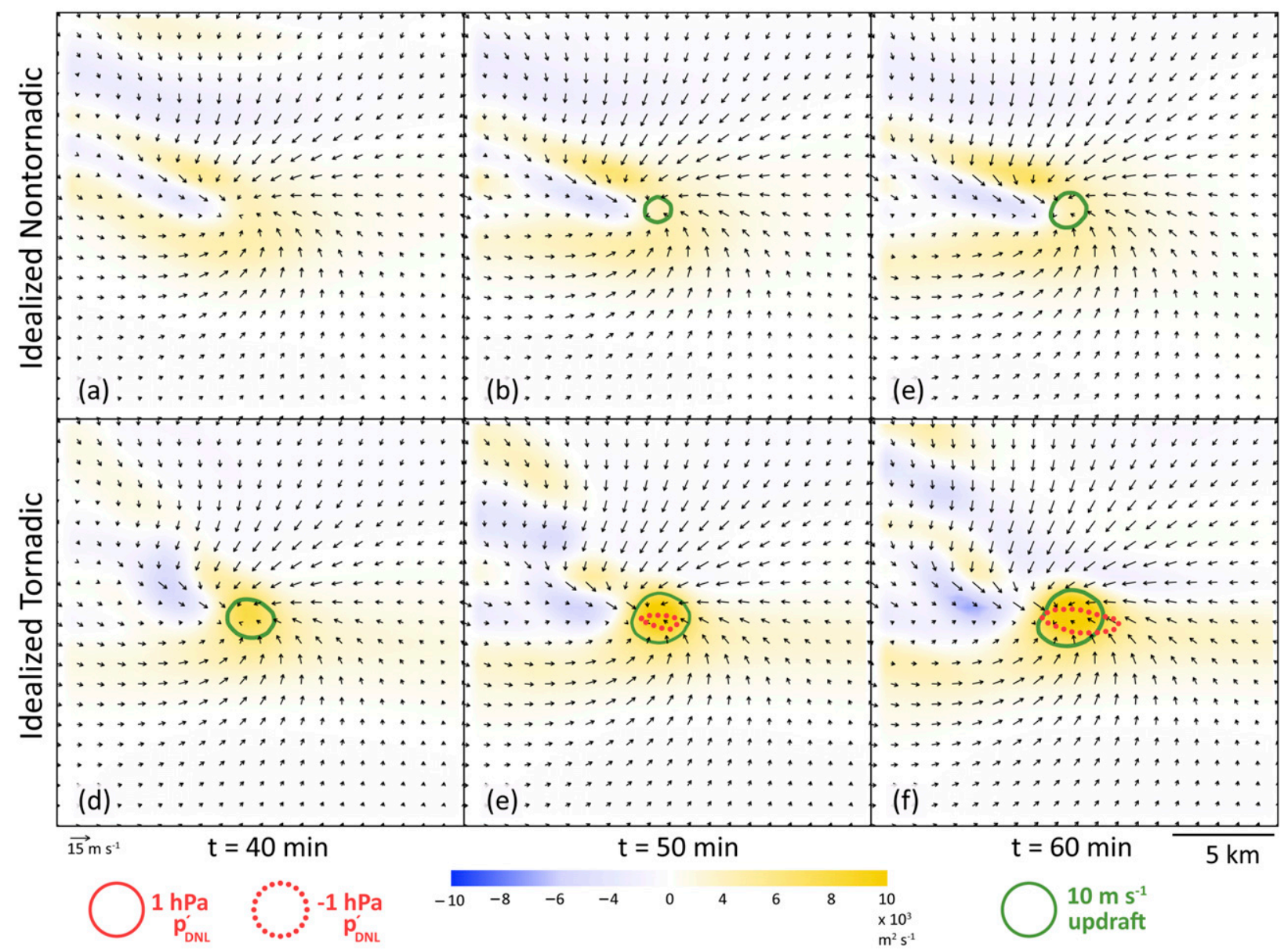

FIG. 21. Horizontal cross sections of circulation $\left(\mathrm{m}^{2} \mathrm{~s}^{-1}\right.$; shaded) at $1 \mathrm{~km}$ computed around a 1-km-radius horizontal ring centered at each grid point at the surface and $1 \mathrm{~km}$ for both the (a)-(c) nontornadic and (d)-(f) tornadic idealized simulations. Also shown is the $10 \mathrm{~m} \mathrm{~s}^{-1}$ vertical velocity contour (green) and the \pm 1 -hPa nonlinear dynamic pressure perturbation $\left(p_{\mathrm{DNL}}^{\prime}\right)$ contour (red, if present) at $1 \mathrm{~km}$ AGL. Vectors represent the perturbation horizontal velocity, plotted every fifth vector.

potential temperature of $300 \mathrm{~K}$ up to $12 \mathrm{~km}$, where a potential temperature inversion of $20 \mathrm{~K} \mathrm{~km}^{-1}$ was added to emulate the tropopause. Otherwise, the model configuration, including the VORTEX2 wind profiles, is identical to the full-physics simulations discussed previously. All differences between the idealized nontornadic and tornadic simulations discussed below are solely due to the wind profile. It should be noted that the model configuration of these idealized updrafts precludes storm splitting and deviant storm motion. In addition, due to the lack of moisture and precipitation, baroclinically generated surface features, such as the vorticity river, are absent. The specific aim of these experiments is to focus on the development of the lowlevel updraft and mesocyclone (i.e., $1 \mathrm{~km} \mathrm{AGL)} \mathrm{and}$ their relation to the wind profile.
Both idealized simulations acquire an approximately steady midlevel updraft and mesocyclone by $20 \mathrm{~min}$. The nontornadic simulation has a maximum vertical velocity of $64 \mathrm{~m} \mathrm{~s}^{-1}$ (similar to the full physics nontornadic VORTEX2 simulation) and maximum vertical vorticity at $3 \mathrm{~km}$ AGL of $0.036 \mathrm{~s}^{-1}$. The tornadic simulation has a weaker upper-level updraft $\left(54 \mathrm{~m} \mathrm{~s}^{-1}\right)$ but similar values of midlevel mesocyclonic vorticity values. The weaker updraft aloft in the tornadic profile, despite identical forcing, is likely due to a more tilted updraft caused by its higher deep-layer shear (Table 1).

A positive feedback loop exists within the simulations. Tilting of horizontal vorticity into the vertical by the updraft leads to rotationally induced pressure falls at midlevels, which enhance the dynamic upward accelerations, thus leading to a stronger updraft (and more 
tilting at lower altitudes). This feedback eventually generates vertical velocities in excess of $10 \mathrm{~m} \mathrm{~s}^{-1}$ in the lowest kilometer in both simulations. Many similarities exist in the circulation field between the idealized and full-physics simulations (cf. Figs. 18, 19, and 21). The 1-km circulation is rapidly intensifying by $t=40 \mathrm{~min}$ in the tornadic idealized simulations (Figs. 21d-f), near the time when the low-level mesocyclone intensifies in the full-physics tornadic simulation. The $1-\mathrm{km}$ circulation is stronger in the tornadic simulation than the nontornadic simulation and is more strongly spatially correlated with the lowlevel updraft (Fig. 21). Just as in the full-physics tornadic supercell, the stronger low-level updraft is driven by a stronger upward-directed dynamic perturbation pressure gradient force (Fig. 22) as the updraft aloft acquires rotation by ingesting storm-relative helicity from the near-surface layer. In contrast, the lowlevel mesocyclone in the nontornadic simulation is characterized by a weaker positive-negative circulation couplet not collocated with the intensifying low-level updraft (Figs. 21a-c).

Bulk characteristics of the low-level mesocyclone in the idealized simulations are evaluated through trajectories. Parcels were launched at every horizontal grid point and every $20 \mathrm{~m}$ vertically in the lowest $2 \mathrm{~km}$ AGL of the inflow region (yielding two million parcels) and integrated forward during the final $30 \mathrm{~min}$ of the idealized simulation. With a focus on the low-level mesocyclone during the last $10 \mathrm{~min}$ of the simulations, only the trajectories that acquired vertical velocity of $10 \mathrm{~m} \mathrm{~s}^{-1}$ and vertical vorticity greater than $0.01 \mathrm{~s}^{-1}$ near $1 \mathrm{~km}$ were analyzed. Despite a similar spatial footprint of inflow parcels in the updraft, over twice as many parcels met these criteria in the tornadic simulation than the nontornadic (5398 vs 2024). All parcels that entered the low-level mesocyclone originated below $530 \mathrm{~m} \mathrm{AGL}$, and the median initial height of the parcels was $270 \mathrm{~m}$ and $110 \mathrm{~m}$ AGL in the nontornadic and tornadic simulation, respectively. As in the fullphysics simulations, parcels that ended up in the tornadic low-level mesocyclone have much larger values of streamwise horizontal vorticity than the nontornadic low-level mesocyclone, and in spite of identical updraft forcing, those tornadic parcels experienced higher vertical velocities and obtained much larger values of vertical vorticity due to more intense stretching (Fig. 23).

These idealized simulations capture the first-order interactions between the wind profile and the updraft. Even in a dry adiabatic environment with identical updraft forcing, the wind profile drives unambiguous differences in the low-level mesocyclone at $1 \mathrm{~km}$

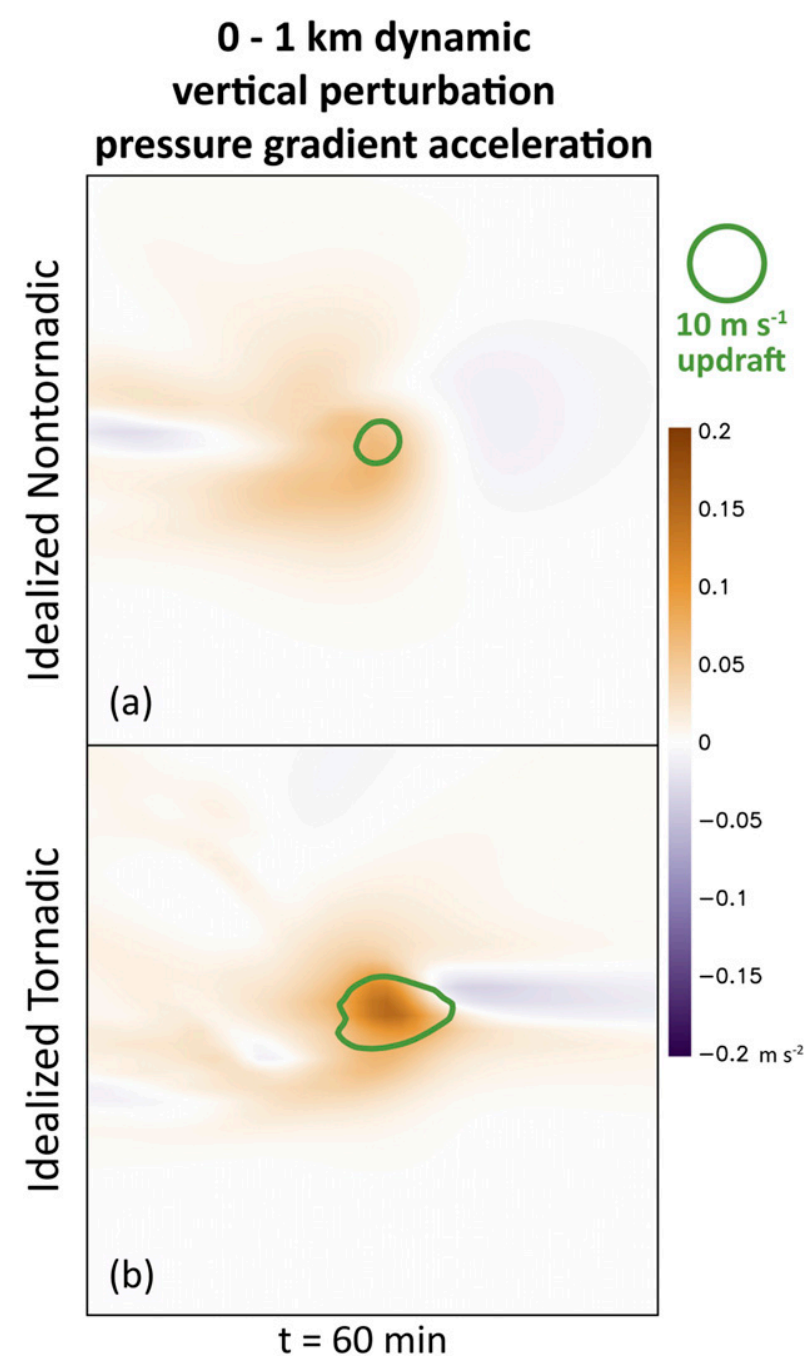

FIG. 22. Horizontal cross sections of $0-1-\mathrm{km}$ dynamic vertical perturbation pressure gradient acceleration ( $\mathrm{m} \mathrm{s}^{-2}$; shaded) and the $10 \mathrm{~m} \mathrm{~s}^{-1}$ vertical velocity contour (green) at $1 \mathrm{~km}$ AGL from the (a) nontornadic and (b) tornadic idealized simulations.

AGL. Thus, in these VORTEX2 composite profiles, the general storm structure, as well as the storm's potential to contract the abundant subtornadic surface vorticity into a tornado, seems to be predominantly governed by the lower-tropospheric environmental wind profile. In the nontornadic case, primarily crosswise vorticity near the surface favors a deformational shear zone behind the updraft, rather than a closed circulation collocated with the updraft. This deformation does not allow the mesocyclone to develop the pressure falls needed for intense dynamic lifting at low levels. In the full-physics simulations, the lack of a mitigating upward-directed vertical perturbation pressure gradient in the nontornadic supercell causes dynamically induced downdrafts to result whenever large 


\section{Low-level mesocyclone parcel characteristics: Idealized simulations}
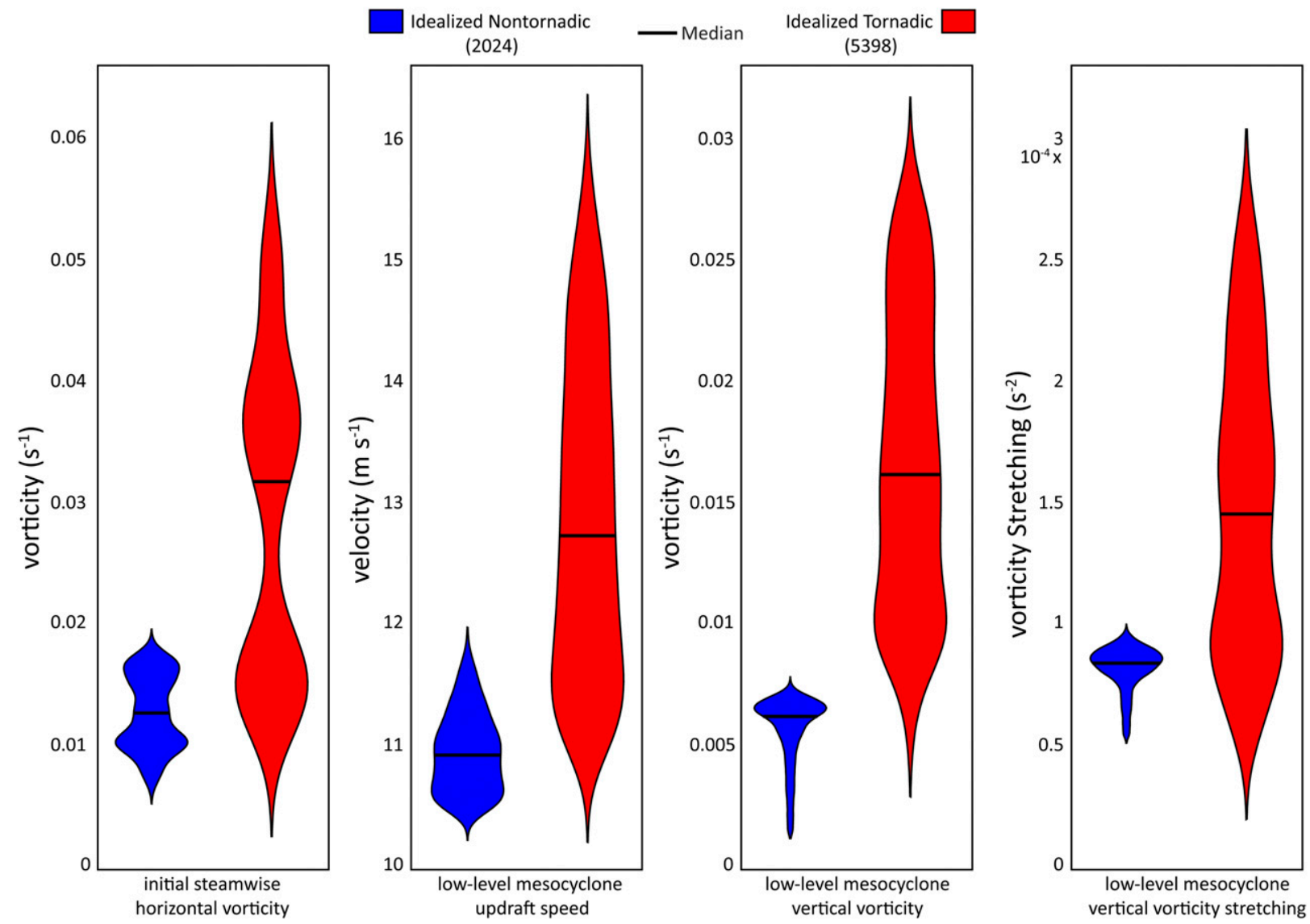

FIG. 23. Smoothed kernel density estimation violin plot of low-level mesocyclone parcel characteristics from the idealized simulations for all parcels that acquired vertical velocity of at least $10 \mathrm{~m} \mathrm{~s}^{-1}$ and vertical vorticity greater than $0.01 \mathrm{~s}^{-1}$ between 950 and $1050 \mathrm{~m}$ AGL. (from left to right) Initial streamwise horizontal vorticity $\left(\mathrm{s}^{-1}\right)$, vertical velocity $\left(\mathrm{m} \mathrm{s}^{-1}\right)$, vertical vorticity ( $\left.\mathrm{s}^{-1}\right)$, and vertical vorticity stretching $\left(\mathrm{m}^{2} \mathrm{~s}^{-2}\right)$ for the nontornadic (blue) and tornadic (red) idealized simulations. The black line represents the median of the distribution, and the total number of low-level mesocyclone parcels is beneath the legend.

surface vorticity develops, preventing the incipient vortex from fully contracting into a tornado.

\section{Synthesis \\ a. Summary}

In this article, we investigated the storm-scale differences between nontornadic and tornadic supercell simulations initialized with the composite VORTEX2 environments. Both the nontornadic and tornadic environments would generally be considered favorable for supercells and tornadoes, with ample CAPE, modest CIN, low LCLs, and sufficient vertical wind shear. While our understanding of environments that favor tornadic versus nontornadic storms has progressed in recent years, it is still unclear how these factors influence the in-storm processes that result in the final steps of the tornadogenesis process. In many respects, nontornadic supercells show remarkable similarity to their tornadic counterparts, and subtornadic-strength surface vertical vorticity is abundant even in nontornadic supercells. We therefore have focused on the final steps that separate tornadogenesis success versus failure. Revisiting the research questions outlined in section 1 , our simulations show the following:

1) Do the two VORTEX2 composite soundings contain sufficiently distinct ingredients to "correctly" simulate nontornadic and tornadic supercells in the respective nontornadic and tornadic environments?

- Simulations in both the nontornadic and tornadic environments produce a strong supercell with a robust midlevel mesocyclone, updraft, and a hook echo reflectivity structure at low altitudes. However, the low-level updraft is much more intense in 


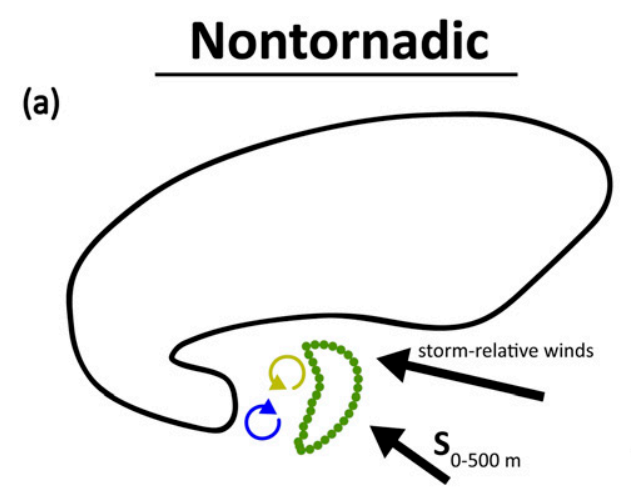

$10 \mathrm{~km}$
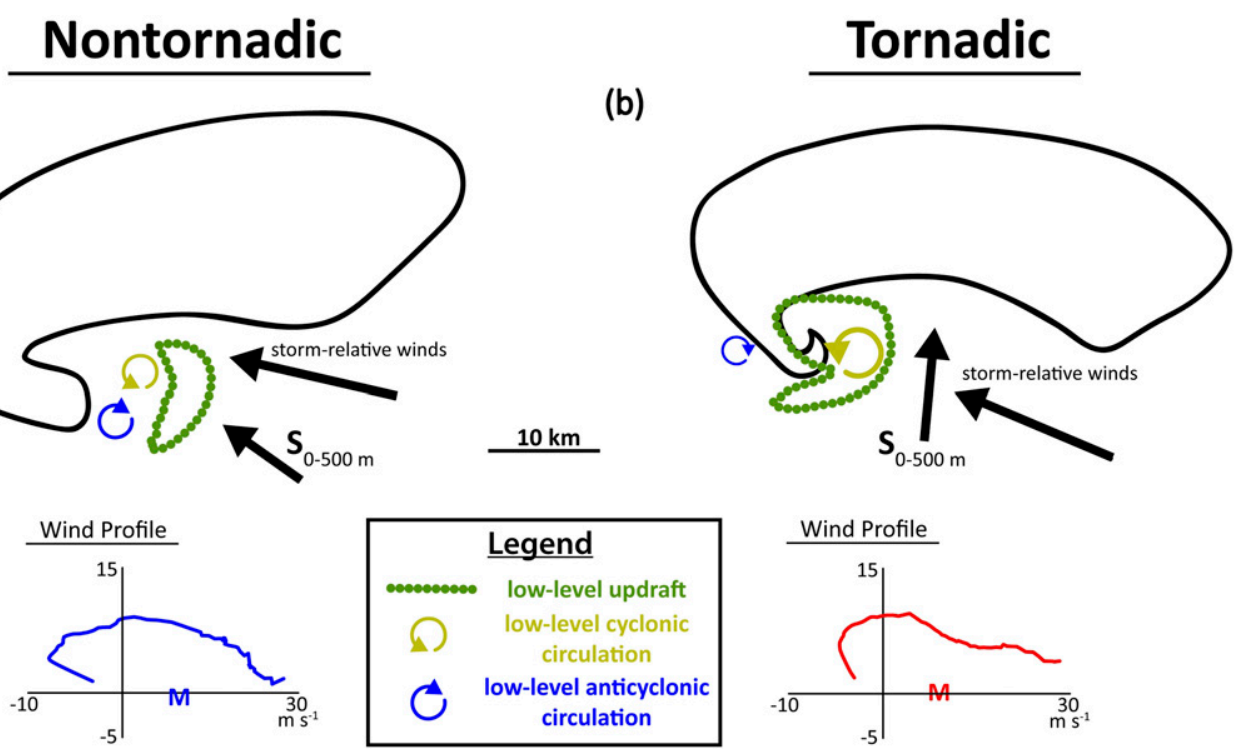

FIG. 24. Conceptual schematic summarizing the key differences between the simulated (a) nontornadic and (b) tornadic supercells. Schematic representations of the 0-500-m shear vector $\left(\mathbf{S}_{0-500 \mathrm{~m}}\right)$, low-level storm-relative winds, low-level updraft (dotted green contour), cyclonic circulation maximum (yellow arrow), and anticyclonic circulation maximum (blue arrow) are presented accordingly. The shear vectors and low-level storm-relative winds are scaled proportionally in $\mathrm{m} \mathrm{s}^{-1}$. Hodograph diagrams showing the nontornadic (blue) and tornadic (red) VORTEX2 wind profiles from Fig. 1 are also given.

the tornadic supercell. The tornadic supercell develops an intense, long-lasting tornado, reaching high-end EF3 wind speeds and lasting for approximately $25 \mathrm{~min}$. The nontornadic supercell only produces shallow vortices that are transient in nature, never reaching the EF0 wind speed threshold. Therefore, even though the differences between the two environments are rather subtle, it does seem that they contain specific ingredients that may discriminate between nontornadic and tornadic supercells.

2) What is the failure point for tornadogenesis in the nontornadic supercell compared to the tornadic supercell?

- The nontornadic supercell readily produces subtornadic values of vertical vorticity at the surface; however, these vortices are not superimposed underneath the low-level updraft and thus fail to attain tornadic intensity due to a lack of convergence and stretching. A disorganized low-level mesocyclone, with no significant dynamic pressure falls, leads to insufficient dynamic lifting and stretching of parcels that acquire surface vertical vorticity. This failure mode occurs despite only weak negative buoyancy in the rear-flank outflow. During the closest attempt at tornadogenesis in the nontornadic supercell, a strong downdraft develops near the axis of rotation, likely due to the circulation at the surface exceeding the circulation aloft in the low-level mesocyclone. This "occlusion-like" downdraft disrupts the developing vortex by inducing near-surface divergence.

3) Can this failure point be specifically traced to some trait that differs between the nontornadic and tornadic environments?

- The disorganized low-level mesocyclone and lack of dynamic lifting in the nontornadic supercell appears to be linked to predominately crosswise vorticity in the lowest few hundred meters in the nontornadic environment. The nontornadic lowlevel mesocyclone is characterized by a cyclonicanticyclonic circulation couplet not collocated with the low-level updraft, a symptom of fluxing horizontal vorticity with a substantial crosswise component into and through the updraft (Fig. 24a). Without the collocation of the updraft and vertical vorticity maxima, the nontornadic supercell does not have a broad, consistent upward-directed vertical perturbation pressure gradient to stretch subtornadic surface vortices into a tornado and to mitigate the downward-directed dynamical accelerations associated with these developing vortices. No such issue exists in the tornadic supercell, as large near-surface streamwise horizontal vorticity is ingested by the updraft, leading to a high correlation between the updraft and low-level 
mesocyclone circulation (Fig. 24b). This results in dynamic perturbation pressure falls within the lowlevel updraft and strong dynamic lifting to stretch high vertical vorticity parcels at the surface into a tornado.

\section{b. Future work}

Although these simulations utilized the VORTEX2 composite environments directly from Parker (2014), simulations utilizing soundings from individual VORTEX2 cases, as well as low- and midlevel wind profile and thermodynamic profile sensitivity tests, are ongoing to systematically study the subtle differences between the nontornadic and tornadic environments. Initial sensitivity tests show that "swapping" the thermodynamic profile between the nontornadic and tornadic environments does not change the conclusions presented above, as the simulated supercells are remarkably similar to those discussed herein (i.e., the outcomes are linked to the respective wind profiles). Another interesting avenue for future analysis of these simulations includes more detailed vorticity budgets [e.g., tracking the barotropic, baroclinic, and/or viscous components of surface vertical vorticity generation during the creation and intensification of subtornadic surface vorticity; Dahl et al. (2014); Markowski (2016)].

Clearly, a complication is that nontornadic and tornadic supercells can coexist side by side in nature. This is an important operational forecasting issue that cannot be easily addressed with single-sounding model studies. Ultimately, an understanding of how environmental ingredients link to the predictability of tornadic versus nontornadic storms may require simulations with added realism, perhaps involving real-world cases and incorporating ensemble techniques (e.g., Snyder and Zhang 2003; Dowell et al. 2004; Marquis et al. 2014, 2016). For these reasons, an ensemble of simulations, with contrasting magnitudes of lower-tropospheric streamwise horizontal vorticity, are planned to investigate the range of outcomes in similar storms and environments, as well as to what extent tornado formation is externally driven by the environmental profile, as opposed to being a stochastic process that is entirely internal to the storm itself.

Acknowledgments. This research was supported by NSF Grant AGS-1156123. We especially thank Dr. George Bryan for his ongoing support of CM1. Dr. Johannes Dahl is acknowledged for sharing his parcel interpolation/identification code, as well as insightful discussion on minimizing friction with the Coriolis force. We also thank Dr. Matthew Bunkers and two anonymous reviewers who helped improve this article. The first author's committee members, Drs. Gary Lackmann, Sandra Yuter, and Johannes Dahl, as well as members of the NCSU Convective Storms group, provided helpful feedback on an earlier version of this manuscript.

\section{REFERENCES}

Adlerman, E. J., K. K. Droegemeier, and R. Davies-Jones, 1999: A numerical simulation of cyclic mesocyclogenesis. J. Atmos. Sci., 56, 2045-2069, doi:10.1175/1520-0469(1999)056<2045: ANSOCM $>2.0 . \mathrm{CO} ; 2$.

Beck, J. R., and C. Weiss, 2013: An assessment of low-level baroclinity and vorticity within a simulated supercell. Mon. Wea. Rev., 141, 649-669, doi:10.1175/MWR-D-11-00115.1.

_ J. L. Schroeder, and J. M. Wurman, 2006: High-resolution dual-Doppler analyses of the 29 May 2001 Kress, Texas, cyclic supercell. Mon. Wea. Rev., 134, 3125-3148, doi:10.1175/ MWR3246.1.

Bluestein, H. B., and S. G. Gaddy, 2001: Airborne pseudo-dualDoppler analysis of a rear-inflow jet and deep convergence zone within a supercell. Mon. Wea. Rev., 129, 2270-2289, doi:10.1175/1520-0493(2001)129<2270:APDDAO > 2.0.CO;2.

_ M. M. French, J. C. Snyder, and J. B. Houser, 2016: Doppler radar observations of anticyclonic tornadoes in cyclonically rotating, right-moving supercells. Mon. Wea. Rev., 144, 15911616, doi:10.1175/MWR-D-15-0304.1.

Brandes, E. A., 1978: Mesocyclone evolution and tornadogenesis: Some observations. Mon. Wea. Rev., 106, 995-1011, doi:10.1175/ 1520-0493(1978)106<0995:MEATSO>2.0.CO;2.

Brotzge, J., S. Erickson, and H. Brooks, 2011: A 5-yr climatology of tornado false alarms. Wea. Forecasting, 26, 534-544, doi:10.1175/WAF-D-10-05004.1.

Bryan, G. H., and H. Morrison, 2012: Sensitivity of a simulated squall line to horizontal resolution and parameterization of microphysics. Mon. Wea. Rev., 140, 202-225, doi:10.1175/ MWR-D-11-00046.1.

Bunkers, M. J., B. A. Klimowski, J. W. Zeitler, R. L. Thompson, and M. L. Weisman, 2000: Predicting supercell motion using a new hodograph technique. Wea. Forecasting, 15, 61-79, doi:10.1175/1520-0434(2000)015<0061:PSMUAN>2.0.CO;2.

Charba, J. P., and Y. Sasaki, 1968: Structure and movement of the severe thunderstorms of 3 April 1964 as revealed from radar and surface mesonetwork data analysis. U.S. Department of Commerce, Environmental Science Services Administration, Research Laboratories, National Severe Storms Laboratory, 47 pp.

Coffer, B. E., and M. D. Parker, 2015: Impacts of increasing low-level shear on supercells during the early evening transition. Mon. Wea. Rev., 143, 1945-1969, doi:10.1175/ MWR-D-14-00328.1.

Craven, J. P., H. E. Brooks, and J. A. Hart, 2004: Baseline climatology of sounding derived parameters associated with deep, moist convection. Natl. Wea. Dig., 28, 13-24.

Dahl, J. M., 2015: Near-ground rotation in simulated supercells: On the robustness of the baroclinic mechanism. Mon. Wea. Rev., 143, 4929-4942, doi:10.1175/MWR-D-15-0115.1.

— M. D. Parker, and L. J. Wicker, 2012: Uncertainties in trajectory calculations within near-surface mesocyclones of simulated supercells. Mon. Wea. Rev., 140, 2959-2966, doi:10.1175/MWR-D-12-00131.1.

,- , and,- 2014 : Imported and storm-generated nearground vertical vorticity in a simulated supercell. J. Atmos. Sci., 71, 3027-3051, doi:10.1175/JAS-D-13-0123.1. 
Davies-Jones, R., 1982: Observational and theoretical aspects of tornadogenesis. Intense Atmospheric Vortices, L. Bengtsson and J. Lighthill, Eds., Springer, 175-189.

_ 1984: Streamwise vorticity: The origin of updraft rotation in supercell storms. J. Atmos. Sci., 41, 2991-3006, doi:10.1175/ 1520-0469(1984)041<2991:SVTOOU>2.0.CO;2.

- 2008: Can a descending rain curtain in a supercell instigate tornadogenesis barotropically? J. Atmos. Sci., 65, 2469-2497, doi:10.1175/2007JAS2516.1.

_ 2015: A review of supercell and tornado dynamics. Atmos. Res., 158-159, 274-291, doi:10.1016/j.atmosres.2014.04.007.

— perspective. The Tornado: Its Structure, Dynamics, Prediction, and Hazards, C. Church et al., Eds., Amer. Geophys. Union, 105-114.

— , R. J. Trapp, and H. B. Bluestein, 2001: Tornadoes and tornadic storms. Severe Convective Storms-An Overview, Meteor. Monogr., No. 50, Amer. Meteor. Soc., 167-221.

Deardorff, J. W., 1980: Stratocumulus-capped mixed layers derived from a three-dimensional model. Bound-Layer Meteor., 18, 495-527, doi:10.1007/BF00119502.

Dowell, D. C., F. Zhang, L. J. Wicker, C. Snyder, and N. A. Crook, 2004: Wind and temperature retrievals in the 17 May 1981 Arcadia, Oklahoma, supercell: Ensemble Kalman filter experiments. Mon. Wea. Rev., 132, 1982-2005, doi:10.1175/ 1520-0493(2004)132<1982:WATRIT>2.0.CO;2.

Emanuel, K. A., 1994: Atmospheric Convection. Oxford University Press, 592 pp.

Esterheld, J. M., and D. J. Giuliano, 2008: Discriminating between tornadic and non-tornadic supercells: A new hodograph technique. Electron. J. Severe Storms Meteor., 3 (2). [Available online at http://www.ejssm.org/ojs/index.php/ejssm/article/ viewArticle/33.]

Frame, J., and P. M. Markowski, 2010: Numerical simulations of radiative cooling beneath the anvils of supercell thunderstorms. Mon. Wea. Rev., 138, 3024-3047, doi:10.1175/ 2010MWR3177.1.

French, M. M., H. B. Bluestein, D. C. Dowell, L. J. Wicker, M. R. Kramar, and A. L. Pazmany, 2008: High-resolution, mobile Doppler radar observations of cyclic mesocyclogenesis in a supercell. Mon. Wea. Rev., 136, 4997-5016, doi:10.1175/ 2008MWR2407.1.

,-- I. PopStefanija, C. A. Baldi, and R. T. Bluth, 2013: Reexamining the vertical development of tornadic vortex signatures in supercells. Mon. Wea. Rev., 141, 4576-4601, doi:10.1175/MWR-D-12-00315.1.

Fujita, T. T., G. S. Forbes, and T. A. Umenhofer, 1976: Close-up view of 20 March 1976 tornadoes: Sinking cloud tops to suction vortices. Weatherwise, 29, 116-145, doi:10.1080/ 00431672.1976 .10544142$.

Grzych, M. L., B. D. Lee, and C. A. Finley, 2007: Thermodynamic analysis of supercell rear-flank downdrafts from Project ANSWERS. Mon. Wea. Rev., 135, 240-246, doi:10.1175/ MWR3288.1.

Jiménez, P. A., J. Dudhia, J. F. González-Rouco, J. Navarro, J. P. Montávez, and E. García-Bustamante, 2012: A revised scheme for the WRF surface layer formulation. Mon. Wea. Rev., 140, 898-918, doi:10.1175/MWR-D-11-00056.1.

Klees, A. M., Y. P. Richardson, P. M. Markowski, C. T. Weiss, J. M. Wurman, and K. Kosiba, 2016: Comparison of the tornadic and nontornadic supercells intercepted by VORTEX2 on 10 June 2010. Mon. Wea. Rev., 144, 3201-3231, doi:10.1175/ MWR-D-15-0345.1.
Klemp, J. B., and R. B. Wilhelmson, 1978: The simulation of three-dimensional convective storm dynamics. J. Atmos. Sci., 35, 1070-1096, doi:10.1175/1520-0469(1978)035<1070: TSOTDC $>2.0 . \mathrm{CO} ; 2$.

- and R. Rotunno, 1983: A study of the tornadic region within a supercell thunderstorm. J. Atmos. Sci., 40, 359-377, doi:10.1175/1520-0469(1983)040<0359:ASOTTR > 2.0.CO;2.

Lemon, L. R., D. W. Burgess, and R. A. Brown, 1978: Tornadic storm airflow and morphology derived from single-Doppler radar measurements. Mon. Wea. Rev., 106, 48-61, doi:10.1175/ 1520-0493(1978)106<0048:TSAAMD>2.0.CO;2.

Lewellen, D., W. Lewellen, and J. Xia, 2000: The influence of a local swirl ratio on tornado intensification near the surface. J. Atmos. Sci., 57, 527-544, doi:10.1175/1520-0469(2000)057<0527: TIOALS $>2.0 . C O ; 2$.

Mansell, E. R., 2010: On sedimentation and advection in multimoment bulk microphysics. J. Atmos. Sci., 67, 3084-3094, doi:10.1175/2010JAS3341.1.

_ C. L. Ziegler, and E. C. Bruning, 2010: Simulated electrification of a small thunderstorm with two-moment bulk microphysics. J. Atmos. Sci., 67, 171-194, doi:10.1175/ 2009JAS2965.1.

Markowski, P. M., 2002: Hook echoes and rear-flank downdrafts: A review. Mon. Wea. Rev., 130, 852-876, doi:10.1175/ 1520-0493(2002)130<0852:HEARFD>2.0.CO;2.

- 2008: A comparison of the midlevel kinematic characteristics of a pair of supercell thunderstorms observed by airborne Doppler radar. Atmos. Res., 88, 314-322, doi:10.1016/ j.atmosres.2007.11.026.

- 2016: An idealized numerical simulation investigation of the effects of surface drag on the development of near-surface vorticity in supercell thunderstorms. J. Atmos. Sci., 73, 43494385, doi:10.1175/JAS-D-16-0150.1.

— latitudes. Wiley-Blackwell, $372 \mathrm{pp}$.

$\longrightarrow$, and — 2014: The influence of environmental low-level shear and cold pools on tornadogenesis: Insights from idealized simulations. J. Atmos. Sci., 71, 243-275, doi:10.1175/ JAS-D-13-0159.1.

-_, and G. H. Bryan, 2016: LES of laminar flow in the PBL: A potential problem for convective storm simulations. Mon. Wea. Rev., 144, 1841-1850, doi:10.1175/ MWR-D-15-0439.1.

—_, J. M. Straka, and E. N. Rasmussen, 2002: Direct surface thermodynamic observations within the rear-flank downdrafts of nontornadic and tornadic supercells. Mon. Wea. Rev., 130, 1692-1721, doi:10.1175/1520-0493(2002)130<1692: DSTOWT $>2.0 . \mathrm{CO} ; 2$.

- C. Hannon, J. Frame, E. Lancaster, A. Pietrycha, R. Edwards, and R. L. Thompson, 2003: Characteristics of vertical wind profiles near supercells obtained from the Rapid Update Cycle. Wea. Forecasting, 18, 1262-1272, doi:10.1175/ 1520-0434(2003)018<1262:COVWPN>2.0.CO;2.

— , Y. P. Richardson, E. Rasmussen, J. Straka, R. DaviesJones, and R. J. Trapp, 2008: Vortex lines within low-level mesocyclones obtained from pseudo-dual-Doppler radar observations. Mon. Wea. Rev., 136, 3513-3535, doi:10.1175/ 2008MWR2315.1.

$\longrightarrow,-$ M. Majcen, J. Marquis, and J. Wurman, 2011: Characteristics of the wind field in three nontornadic low-level mesocyclones observed by the Doppler on Wheels radars. Electron. J. Severe Storms Meteor., 6 (3). [Available online at http://www. ejssm.org/ojs/index.php/ejssm/article/viewArticle/75.] 
_ , and Coauthors, 2012a: The pretornadic phase of the Goshen County, Wyoming, supercell of 5 June 2009 intercepted by VORTEX2. Part I: Evolution of kinematic and surface thermodynamic fields. Mon. Wea. Rev., 140, 2887-2915, doi:10.1175/MWR-D-11-00336.1.

_ - , and Coauthors, 2012b: The pretornadic phase of the Goshen County, Wyoming, supercell of 5 June 2009 intercepted by VORTEX2. Part II: Intensification of low-level rotation. Mon. Wea. Rev., 140, 2916-2938, doi:10.1175/ MWR-D-11-00337.1.

— , Y. Richardson, and G. Bryan, 2014: The origins of vortex sheets in a simulated supercell thunderstorm. Mon. Wea. Rev., 142, 3944-3954, doi:10.1175/MWR-D-14-00162.1.

Marquis, J., Y. Richardson, P. Markowski, D. Dowell, and J. Wurman, 2012: Tornado maintenance investigated with high-resolution dual-Doppler and EnKF analysis. Mon. Wea. Rev., 140, 3-27, doi:10.1175/MWR-D-11-00025.1.

$-,-\longrightarrow,-, \quad-$ K. Kosiba, P. Robinson, and G. Romine, 2014: An investigation of the Goshen County, Wyoming, tornadic supercell of 5 June 2009 using EnKF assimilation of mobile mesonet and radar observations collected during VORTEX2. Part I: Experiment design and verification of the EnKF analyses. Mon. Wea. Rev., 142, 530-554, doi:10.1175/MWR-D-13-00007.1.

_ - — - - - J. Wurman, K. Kosiba, and P. Robinson, 2016: An investigation of the Goshen County, Wyoming, tornadic supercell of 5 June 2009 using EnKF assimilation of mobile mesonet and radar observations collected during VORTEX2. Part II: Mesocyclone-scale processes affecting tornado formation, maintenance, and decay. Mon. Wea. Rev., 144, 3441-3463, doi:10.1175/ MWR-D-15-0411.1.

Naylor, J., and M. S. Gilmore, 2012: Convective initiation in an idealized cloud model using an updraft nudging technique. Mon. Wea. Rev., 140, 3699-3705, doi:10.1175/ MWR-D-12-00163.1.

Nolan, D. S., 2013: On the use of Doppler radar-derived wind fields to diagnose the secondary circulations of tornadoes. J. Atmos. Sci., 70, 1160-1171, doi:10.1175/JAS-D-12-0200.1.

Nowotarski, C. J., 2015: Low-level shear in the near-storm environment of simulated supercells and impacts of shear orientation on outflow characteristics. 16th Conf. on Mesoscale Processes, Boston, MA, Amer. Meteor. Soc., 3.1. [Available online at https://ams.confex.com/ams/16Meso/webprogram/ Paper274760.html.]

— , P. M. Markowski, Y. P. Richardson, and G. H. Bryan, 2015: Supercell low-level mesocyclones in simulations with a sheared convective boundary layer. Mon. Wea. Rev., 143, 272 297, doi:10.1175/MWR-D-14-00151.1.

Okubo, A., 1970: Horizontal dispersion of floatable particles in the vicinity of velocity singularities such as convergences. DeepSea Res., 17 (3), 445-454.

Parker, M. D., 2012: Impacts of lapse rates on low-level rotation in idealized storms. J. Atmos. Sci., 69, 538-559, doi:10.1175/ JAS-D-11-058.1.

— 2 2014: Composite VORTEX2 supercell environments from near-storm soundings. Mon. Wea. Rev., 142, 508-529, doi:10.1175/MWR-D-13-00167.1.

—, and J. M. Dahl, 2015: Production of near-surface vertical vorticity by idealized downdrafts. Mon. Wea. Rev., 143, 27952816, doi:10.1175/MWR-D-14-00310.1.

Potvin, C. K., K. L. Elmore, and S. J. Weiss, 2010: Assessing the impacts of proximity sounding criteria on the climatology of significant tornado environments. Wea. Forecasting, 25, 921930, doi:10.1175/2010WAF2222368.1.

Rasmussen, E. N., 2003: Refined supercell and tornado forecast parameters. Wea. Forecasting, 18, 530-535, doi:10.1175/ 1520-0434(2003) $18<530:$ RSATFP $>2.0$. CO 2 .

_, and D. O. Blanchard, 1998: A baseline climatology of soundingderived supercell and tornado forecast parameters. Wea. Forecasting, 13, 1148-1164, doi:10.1175/1520-0434(1998)013<1148: $\mathrm{ABCOSD}>2.0 . \mathrm{CO} ; 2$.

__ and J. M. Straka, 2007: Evolution of low-level angular momentum in the 2 June 1995 Dimmitt, Texas, tornado cyclone. J. Atmos. Sci., 64, 1365-1378, doi:10.1175/ JAS3829.1.

_ — - R. Davies-Jones, C. A. Doswell III, F. H. Carr, M. D. Eilts, and D. R. MacGorman, 1994: Verification of the Origins of Rotation in Tornadoes Experiment: VORTEX. Bull. Amer. Meteor. Soc., 75, 995-1006, doi:10.1175/ 1520-0477(1994)075<0995:VOTOOR > 2.0.CO;2.

Roberts, B., M. Xue, A. D. Schenkman, and D. T. Dawson, 2016: The role of surface drag in tornadogenesis within an idealized supercell simulation. J. Atmos. Sci., 73, 3371-3395, doi:10.1175/JAS-D-15-0332.1.

Rotunno, R., 2013: The fluid dynamics of tornadoes. Annu. Rev. Fluid Mech., 45, 59-84, doi:10.1146/annurev-fluid-011212-140639.

, and J. Klemp, 1985: On the rotation and propagation of simulated supercell thunderstorms. J. Atmos. Sci., 42, 271-292, doi:10.1175/1520-0469(1985)042<0271:OTRAPO >2.0.CO;2.

Schenkman, A. D., M. Xue, and M. Hu, 2014: Tornadogenesis in a high-resolution simulation of the 8 May 2003 Oklahoma City supercell. J. Atmos. Sci., 71, 130-154, doi:10.1175/ JAS-D-13-073.1.

Shu, C.-W., 2003: High-order finite difference and finite volume WENO schemes and discontinuous Galerkin methods for CFD. Int. J. Comput. Fluid Dyn., 17, 107-118, doi:10.1080/ 1061856031000104851.

Skinner, P. S., C. C. Weiss, M. M. French, H. B. Bluestein, P. M. Markowski, and Y. P. Richardson, 2014: VORTEX2 observations of a low-level mesocyclone with multiple internal rearflank downdraft momentum surges in the 18 May 2010 Dumas, Texas, supercell. Mon. Wea. Rev., 142, 2935-2960, doi:10.1175/ MWR-D-13-00240.1.

Snyder, C., and F. Zhang, 2003: Assimilation of simulated Doppler radar observations with an ensemble Kalman filter. Mon. Wea. Rev., 131, 1663-1677, doi:10.1175//2555.1.

Straka, J. M., E. N. Rasmussen, R. P. Davies-Jones, and P. M. Markowski, 2007: An observational and idealized numerical examination of low-level counter-rotating vortices in the rear flank of supercells. Electron. J. Severe Storms Meteor., 2 (8). [Available online at http://www.ejssm.org/ojs/index.php/ ejssm/article/viewArticle/32.]

Thompson, R. L., R. Edwards, J. A. Hart, K. L. Elmore, and P. Markowski, 2003: Close proximity soundings within supercell environments obtained from the Rapid Update Cycle. Wea. Forecasting, 18, 1243-1261, doi:10.1175/ 1520-0434(2003)018<1243:CPSWSE > 2.0.CO;2.

, C. M. Mead, and R. Edwards, 2007: Effective storm-relative helicity and bulk shear in supercell thunderstorm environments. Wea. Forecasting, 22, 102-115, doi:10.1175/WAF969.1.

— B. T. Smith, J. S. Grams, A. R. Dean, and C. Broyles, 2012: Convective modes for significant severe thunderstorms in the contiguous United States. Part II: Supercell and QLCS tornado environments. Wea. Forecasting, 27, 1136-1154, doi:10.1175/ WAF-D-11-00116.1. 
Trapp, R. J., 1999: Observations of nontornadic low-level mesocyclones and attendant tornadogenesis failure during VORTEX. Mon. Wea. Rev., 127, 1693-1705, doi:10.1175/ 1520-0493(1999)127<1693:OONLLM > 2.0.CO;2.

_, and R. Davies-Jones, 1997: Tornadogenesis with and without a dynamic pipe effect. J. Atmos. Sci., 54, 113-133, doi:10.1175/ 1520-0469(1997)054<0113:TWAWAD>2.0.CO;2.

_ G. J. Stumpf, and K. L. Manross, 2005: A reassessment of the percentage of tornadic mesocyclones. Wea. Forecasting, 20, 680-687, doi:10.1175/WAF864.1.

Wakimoto, R. M., and H. Cai, 2000: Analysis of a nontornadic storm during VORTEX 95. Mon. Wea. Rev., 128, 565-592, doi:10.1175/1520-0493(2000)128<0565:AOANSD>2.0.CO;2.

- — - and H. V. Murphey, 2004: The Superior, Nebraska, supercell during BAMEX. Bull. Amer. Meteor. Soc., 85, 10951106, doi:10.1175/BAMS-85-8-1095.

Weiss, J., 1991: The dynamics of enstrophy transfer in two-dimensional hydrodynamics. Physica D, 48, 273-294, doi:10.1016/ 0167-2789(91)90088-Q.

Wicker, L. J., and R. B. Wilhelmson, 1995: Simulation and analysis of tornado development and decay within a three-dimensional supercell thunderstorm. J. Atmos. Sci., 52, 2675-2703, doi:10.1175/1520-0469(1995)052<2675: SAAOTD $>2.0 . \mathrm{CO} ; 2$.

_- , and W. C. Skamarock, 2002: Time-splitting methods for elastic models using forward time schemes. Mon. Wea. Rev., 130, 2088-2097, doi:10.1175/1520-0493(2002)130<2088: TSMFEM $>2.0 . \mathrm{CO} ; 2$.

Wilhelmson, R. B., and C.-S. Chen, 1982: A simulation of the development of successive cells along a cold outflow boundary. J. Atmos. Sci., 39, 1466-1483, doi:10.1175/ 1520-0469(1982)039<1466:ASOTDO > 2.0.CO;2.

Wurman, J., D. Dowell, Y. Richardson, P. Markowski, E. Rasmussen, D. Burgess, L. Wicker, and H. B. Bluestein, 2012: The second Verification of the Origins of Rotation in Tornadoes Experiment: VORTEX2. Bull. Amer. Meteor. Soc., 93, 1147-1170, doi:10.1175/BAMS-D-11-00010.1.

Ziegler, C. L., 1985: Retrieval of thermal and microphysical variables in observed convective storms. Part I: Model development and preliminary testing. J. Atmos. Sci., 42, 1487-1509, doi:10.1175/1520-0469(1985)042<1487: ROTAMV $>2.0 . \mathrm{CO} ; 2$. 